\title{
Global changes in a humidity index between 1931-60 and 1961-90
}

\author{
M. Hulme', R. Marsh'², P. D. Jones ${ }^{1}$ \\ ${ }^{1}$ Climatic Research Unit, School of Environmental Sciences, University of East Anglia, Norwich NR4 7TJ, UK \\ ${ }^{2}$ James Rennell Centre for Ocean Circulation, Gamma House, Chilworth Research Centre, Southampton SO1 7NS, UK
}

\begin{abstract}
As part of the 1992 global reassessment of the status of desertification, the United Nations Environment Programme (UNEP) required a new baseline climatology to be prepared to define the world's drylands within which, according to their adopted definition, desertification may occur. The desertification assessment presented at the 1977 UN Conference on Desertification in Nairobi used the ratio of amnual precipitation to potential evapotranspiration (P/PE) as a simple and appropriate index of humidity to define the drylands of the world. Using global data sets of temperature and precipitation held by the Climatic Research Unit, an annual humidity index (HI) was calculated on a $5^{\circ}$ resolution for 2 independent $30 \mathrm{yr}$ periods, 1931-60 and 1961-90. PE was calculated from surface air temperature using the Thornthwaite method. There is a systematic bias in Thornthwaite PE estimates which tends to increase $\mathrm{HI}$ in arid regions and seasons, and decrease $\mathrm{HI}$ in cold climates. This bias has implications for the determination of dryland boundaries. Using selected regional data sets of Penman PE estimates for Europe and Sudan, an empirical adjustment to annual Thornthwaite PE was therefore derived and applied to the global PE fields. The adjusted HI values for the 2 observed 30 yr periods were compared. An assessment was made of the sensitivity of dryland boundaries in Africa to recent climatic change. Between 1931-60 and 1961-90,7.3\% of the continent has shifted into a drier moisture zone and only $1.7 \%$ into a wetter zone. The net areas of hyper-arid and arid lands in Africa have increased from $1931-60$ to $1961-90$ by 50 and 3 million hectares respectively.
\end{abstract}

\section{INTRODUCTION}

The 1977 United Nations Conference on Desertification (UNCOD) held in Nairobi included the first assessment of the worldwide extent of desertification. In the Plan of Action to Combat Desertification (PACD), endorsed by UNCOD, the target year of 2000 was selected for bringing the problem of desertification under control. Following the 1984 interim evaluation of the PACD (UNEP 1984), the next major global reassessment of the extent of desertification is due in 1992 and will be presented by UNEP/GEMS at the United Nations Conference on Environment and Development (UNCED) to be held in Rio de Janeiro in June 1992 (Odingo 1990). One of the critical data sets used in this reassessment will be a revised global moisture index which will define the extent of the world's drylands within which desertification, as defined by UNEP, may occur:
'Desertification/land degradation, in the context of assessment, is land degradation in arid, semi-arid and dry sub-humid (i.e. dryland) areas resulting from adverse human impact.' (Odingo 1990, p. 3).

In the 1977 UNCOD assessment the global map of aridity was prepared by FAO/UNESCO/WMO (1977). This map was constructed from climatological means originating from a variety of sources but mostly representative of the period 1931-60. The aridity index was defined as the ratio of precipitation to potential evapotranspiration (P/PE).

This aridity map required updating for the 1992 UNEP/GEMS assessment for several reasons. First, the baseline data used by FAO/UNESCO/WMO is now dated. A new 1961-90 climatological normal period (WMO 1989) is now complete and more recent data should be used to reflect the climate of the last $30 \mathrm{yr}$, i.e. a climatology representative of 1931-60 should not be used for the assessment of desertification during the 
1970 s and 1980s. Second, the FAO/UNESCO/WMO aridity exists only in map form and not as a georeferenced data set. For the new aridity index to be incorporated into the automated analysis in the 1992 assessment, a new geo-referenced climatology was required. Third, the procedure for determining the FAO/UNESCO/WMO aridity surface was not completely transparent. For example, the number, source and quality control of the station data which contributed to the map was not specified, and the interpolation procedure allowed for extensive subjective alteration to the aridity boundaries where it was deemed necessary.

The work described in this paper arose from the Climatic Research Unit (CRU) being commissioned by UNEP/GEMS to prepare a new global data set and aridity index for use in the 1992 reassessment of desertification. The index used (P/PE) is actually a measure of moisture surplus, therefore we refer to the index as a humidity index (HI) where higher index values imply greater humidity. Three separate products were generated (Hulme \& Marsh 1990): a global HI map based on quality-controlled station data covering the period 1951-80 (the 30 yr period of best available station coverage); humidity indices for 2 independent 30 yr periods, $1930-59$ and 1960-89; and a projected HI representative of the year 2030 assuming a 'business-as-usual' scenario of greenhouse gas emissions (Houghton et al. 1990). While elements of all 3 products will be included in the World Atlas of Desertification accompanying the 1992 reassessment (UNEP 1992), this paper will concentrate on the methodology for constructing the index and on presenting the change in humidity between 2 independent periods: 1931-60 and 1961-90.

We first describe the temperature and precipitation data sets used in the analysis and the methods used for constructing the global climatologies. The spatial pattern of change in global climate between 1931-60 and 1961-90 is then briefly discussed. The second part of the paper explains the construction of the $\mathrm{HI}$ using the $\mathrm{P} / \mathrm{PE}$ ratio originally proposed by FAO/UNESCO/ WMO and presents the change in this index over the $60 \mathrm{yr}$ period. Some area calculations are made for the African continent. Finally, the significance of these changes both for desertification and for regional and global climate change is addressed.

\section{CONSTRUCTING THE CLIMATOLOGIES}

\section{Data sets}

Published climatological 'normals' for monthly surface air temperature and monthly precipitation exist for numerous meteorological stations worldwide. These normals, or averages, are usually based on meteorological observations over a 30 yr period, although often the station record may contain a few missing years within this period. For most published sources the 30 yr period used is $1931-60,1941-70$ or 1951-80. It is not uncommon, however, for no period to be specified (e.g. Müller 1982). These inconsistencies in reference periods restrict the use that may be made of such station means, and limit greatly the number of stations which may be used in a comparison of 2 independent $30 \mathrm{yr}$ periods. If the requirement for specific and consistent reference periods is dropped, however, then large numbers of station means are available. Legates \& Willmott (1990), for example, used over 25000 station means for constructing a global precipitation climatology, although the resulting climatology is 'timeless' rather than 'time-dependent' and therefore has restricted application.

Rather than rely on published climatological normals we used the monthly temperature and precipitation data sets held in CRU and prepared over a period of years (Jones et al. 1985, 1986a, Eischeid et al. 1991, Hulme 1991). These data sets hold time series of monthly-mean surface air temperature and monthly precipitation totals for several thousand terrestriallybased stations worldwide. These station time series vary in length from less than $10 \mathrm{yr}$ to over $200 \mathrm{yr}$ in the case of several European stations. Both data sets are updated routinely using CLIMAT reports (issued by member countries of WMO), data published regularly in Monthly Climatic Data for the World, station observations communicated directly to CRU by certain National Meteorological Authorities through monthly or annual national reports, and country data sets supplied by collaborating scientists and institutes. The advantage of using these data sets as a source of climatological normals is that any required reference period may be extracted. Thus, we are not limited to standard WMO periods, nor to periods for which published normals are available.

The CRU temperature data set contains time series of monthly mean surface air temperatures $\left({ }^{\circ} \mathrm{C}\right)$ for 3417 stations worldwide. These consist of 2666 Northern Hemisphere stations (as listed in Jones et al. 1985) plus an additional 751 Southern Hemisphere stations (Jones et al. 1986a). These time series have been assessed for homogeneity and screened for outliers (Jones et al. 1985, 1986a). Station time series which were either too short to be assessed for homogeneity or failed to meet the homogeneity criteria were either corrected or excluded from further analysis. Exclusions included a number of station series where urbanisation during the twentieth century had created spurious warming trends. Full details of all exclusions and the adjustments made to some records are given in the above 2 references. 
The CRU precipitation data set contains time series of monthly precipitation totals (mm) for 7336 stations worldwide. These consist of 5097 Northern Hemisphere stations and 2239 Southern Hemisphere stations. These time series have been screened for outliers and discontinuities, but have not been comprehensively assessed for homogeneity (Hulme 1992). Although site and instrumentation changes will introduce inhomogeneities into the time series, the magnitude and direction of such biases is generally less obvious than for temperature. For example, in precipitation time series there is no parallel to the systematic urban warming bias which affects some temperature series, although some may argue that precipitation downwind of urban areas may be enhanced (Landsberg 1981). Different problems, such as the varying treatment of snowfall (Groisman et al. 1991), will nevertheless contaminate some of these station precipitation series. Problems such as these lead us to prefer the use of gridded data sets rather than individual station series to generate climate surfaces for both mean temperature and precipitation - the process of gridding reduces the influence of random biases in individual station series.

The additional problem of the systematic undercatch of precipitation gauges is also not addressed in these precipitation station series. Sophisticated correction procedures involving a large number of variables (e.g. gauge design, sheltering, wind velocity, evaporation, wetting loss, etc.) have been devised for wellinstrumented stations (Sevruk 1982). Applying such corrections to a global data set, where many stations possess few other meteological observations, is not regarded as feasible at the present time. Legates \& Willmott (1990) suggest, however, that for these reasons of gauge undercatch, global precipitation estimates may be 10 to $12 \%$ too low. This is a substantial source of potential systematic error, although for the purposes of the current exercise where we are comparing two 30 yr climatologies it should not greatly affect the results.

\section{Gridding methods}

Previous work by CRU has established an objective procedure for combining temperature data onto a regular grid. This procedure is in effect an interpolation method using inverse distance weighting. Full details of the basic method can be found in Jones et al. (1986b). There are several advantages of using this gridded temperature data set for our current purposes. First, the data set has been extensively analysed for robustness and representativeness of global temperature change (see for example Jones et al. 1986c, 1989,
Jones 1988, Karl \& Jones 1989). Second, the terrestrial station data held by CRU have been supplemented with sea surface temperature anomalies contained in the Comprehensive Ocean-Atmosphere Data Set (COADS) (see Woodruff et al. 1987). This marine data set has been merged with the CRU terrestrial data set to produce as extensive as possible global-mean temperature time series (Jones \& Wigley 1990, Jones et al. 1991). Where gridboxes contained both sea surface and terrestrial temperature anomaly values, these were averaged to produce a single gridbox temperature. Third, the gridded data set is generated on a regular $5^{\circ}$ latitude/longitude grid ensuring direct compatibility both with other gridded observed data sets and with climate fields generated by General Circulation Model (GCM) experiments.

The gridded temperature data set exists as a continuously updated monthly time series commencing in 1854. Coverage is restricted mainly to Europe and some coastal areas during the 1850 s and gradually expands to near-global coverage in the 1980s. Almost all land areas except Antarctica are completely covered during the 1931-90 period. For terrestrial data, the scaling of station temperatures in anomaly units is essential when combining records from stations at different altitudes and with different methods of calculating monthly-mean temperature (Jones et al. $1986 \mathrm{~b})$. The temperature time series are therefore held as ${ }^{\circ} \mathrm{C}$ anomalies from a reference period - in our case $1950-79$ is used for this purpose. For determining the two 30 yr climatologies to be analysed here, these anomaly units needed converting into absolute surface air temperatures. This was achieved by first adding the gridded anomalies to a reference mean sea level global gridded temperature climatology for 1950-79 and then adjusting these temperatures for altitude using a standard lapse rate of $0.6{ }^{\circ} \mathrm{C}$ per $100 \mathrm{~m}$. Mean gridbox. elevations were derived from a global digital terrain model. Mean gridbox temperatures were then extracted for the 2 periods, 1931-60 and 1961-90. Following WMO guidelines for calculating temperature normals (WMO 1989), a gridbox required data for a minimum of 21 out of $30 \mathrm{yr}$ (i.e. $70 \%$ ) for monthly means to be calculated. This resulted in 1384 (out of a maximum of 2592) gridboxes possessing valid temperature means for both periods (Table 1). The distribution of these boxes is shown in Fig. 1 .

A different approach for generating gridded precipitation means from station time series was necessary. There are a number of objective methods for generating areal estimates of precipitation from gauge networks, the most common being simple arithmetic means, nearest neighbour approaches such as Thiessen polygons, spline surface fitting (e.g. Hutchinson 1991), and universal kriging (e.g. Delfine \& 
Table 1. Number of $5^{\circ} \mathrm{gridboxes}$ included in each 30 yr period for temperature. A gridbox had to meet the criterion of at least 21 valid observations in all months. A box had to pass these criteria in both 1931-60 and 1961-90 periods to be included in the 'Both' subset

\begin{tabular}{|c|c|c|c|c|}
\hline Period & $\begin{array}{c}\text { No. of } 5^{\circ} \\
\text { boxes selected }\end{array}$ & $\begin{array}{l}\text { Total no. } \\
\text { of } 5^{\circ} \text { boxes }\end{array}$ & $\begin{array}{c}\% \\
\text { global boxes }\end{array}$ & $\begin{array}{c}\% \\
\text { surface area }\end{array}$ \\
\hline $1931-60$ & 1386 & 2592 & 53 & 67 \\
\hline $1961-90$ & 1661 & 2592 & 64 & 79 \\
\hline Both & 1384 & 2592 & 53 & 67 \\
\hline
\end{tabular}

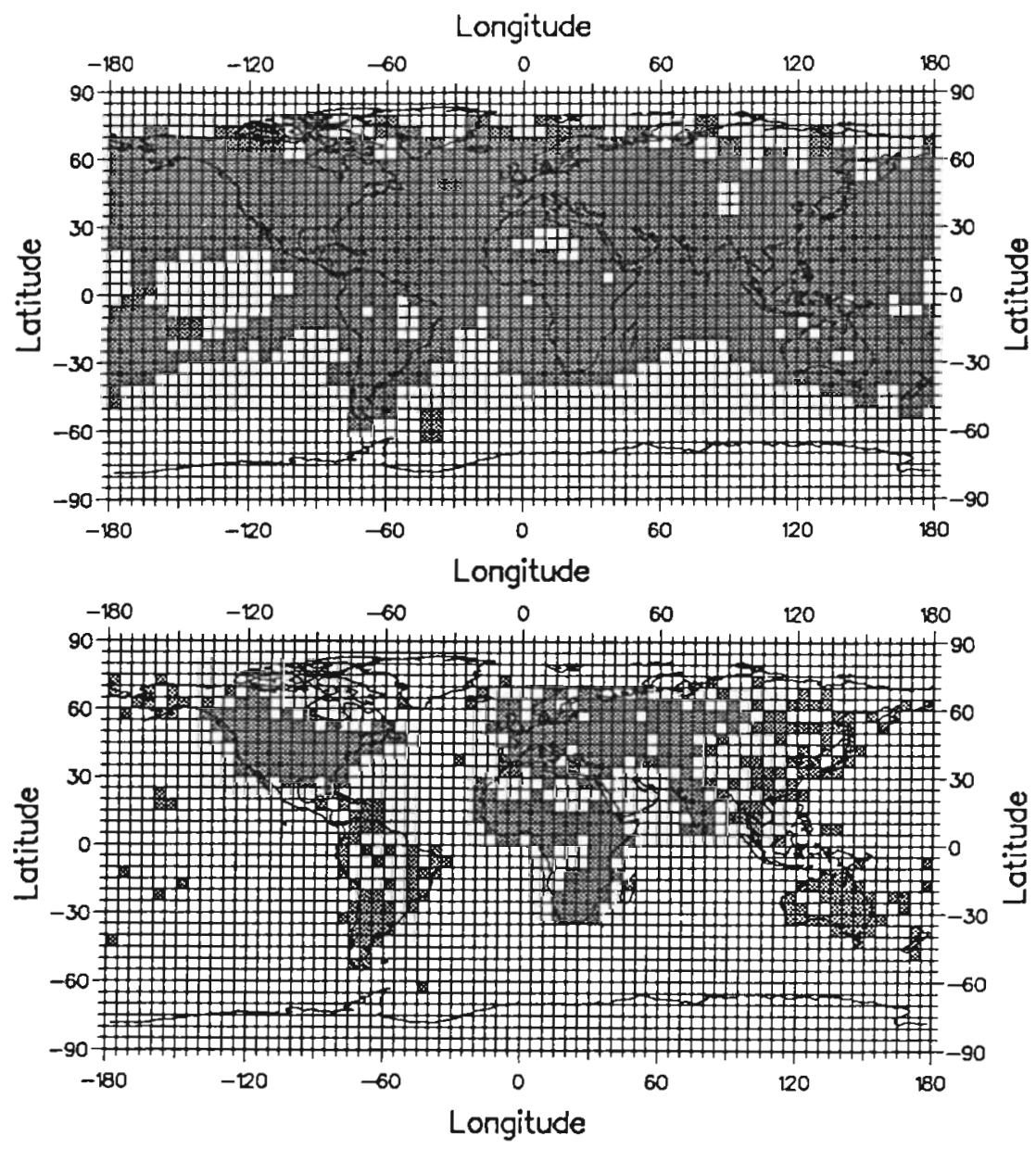

Fig. 1. Distribution of $5^{\circ}$ gridboxes for which (upper) temperature means and (lower) precipitation means were calculated for both 1931-60 and 1961-90

smaller with longer time-steps and with denser gauge networks. Although the precipitation data set used here is relatively low density (for land areas a global average of 1 gauge per $24700 \mathrm{~km}^{2}$ or about 7 gauges per $5^{\circ}$ gridbox), the errors of using the Thiessen method are reduced because monthly precipitation totals were being estimated. Nevertheless, areal estimates made using Thiessen polygons are sensitive to clustered data and this problem affects a small number of the gridboxes used. Furthermore, 2 disadvantages of kriging methods are their computational complexity and their rigourous assumptions about isotropic climatological variograms (Lebel et al. 1987) which would be hard to justify gridbox-by-gridbox on a global basis.

Gridded areal precipitation estimates were therefore generated using a Thiessen polygon approach. Here, each gridbox is divided into $n$ zones of influence, one for each gauge. The zone of influence of a gauge is defined by the polygonal area which is closer to that gauge than to any other. The gridbox precipitation estimate is then the weighted average of the $n$ gauges falling within the gridbox (full details are in Hulme (1992) where

Delhomme 1973). These objective estimation techniques have been reviewed by Creutin \& Obled (1982) and quantitatively evaluated for short time-scale precipitation events by Lebel et al. (1987). They clearly show that for sub-daily precipitation and for sparse gauge networks, kriging methods are preferred and that simple areal estimation techniques such as Thiessen polygons can produce large estimation errors. Such errors, however, become progressively the same approach was used to generate a gridded climatology for use in validating GCMs]. WMO guidelines for calculating precipitation $30 \mathrm{yx}$ normals suggest that data should be present for 25 out of $30 \mathrm{yr}$, i.e. $83 \%$ (WMO 1989). Because of the large variability of precipitation over space, we need to ensure either that the same stations contribute to both the 1931-60 and 1961-90 gridded climatologies or that the precipitation units are scaled in such a way that the resulting 
gridbox estimates are independent of the configuration of the network of gauges within the gridbox. In the case of temperature, the latter procedure was adopted by converting absolute temperatures to temperature anomalies from a reference-period mean. With precipitation, we cannot use this method since the equivalent scaling for precipitation (percentages from a referenceperiod mean) becomes highly unstable on a year-byyear basis in arid and semi-arid regions and seasons. If, however, we adopt the former solution and insist that only those stations which meet the $83 \%$ criterion over both $30 \mathrm{yr}$ periods are included in the gridding, we will greatly restrict the number of contributing stations (only 2345 stations out of 7336 will be thus selected, Table 2). An alternative solution is therefore required to this problem.

The best station coverage in the CRU precipitation data set occurs for the decades between 1940 and 1980. If we calculate a gridded mean precipitation climatology using the Thiessen method described above for the period 1946-75, then the maximum possible number of stations will be included (4404 stations meet the $83 \%$ criterion for $1946-75$; cf. Table 2, Fig. 2). With the reference climatology established for the high coverage period, relative climatologies can then be derived for the required periods 1931-60 and 1961-90. Station means for these two $30 \mathrm{yr}$ periods are converted into station percentages with respect to the 1946-75 station means. These 2 sets of station percentages are then averaged over each gridbox for 1931-60 and 1961-90 using Thiessen weightings. The resulting mean gridbox percentages are converted back into mm estimates for 1931-60 and 1961-90 using the gridbox means previously established for the 1946-75 reference period.
This procedure is somewhat similar to one of the solutions mentioned above (namely scaling precipitation units) except that the percentage scaling is performed only on the time-mean station data (percentages of mean precipitation are more robust than those of individual monthly or annual values). We still preserve the advantage of scaling, however, in that stations can contribute to the gridded climatologies even if they do not meet the missing data criterion for both 1931-60 and 1961-90. In effect, a station can be used if it meets the $83 \%$ criterion for either the $1931-75$ or $1946-90$ periods. This enables several hundred more stations to be used than the 2345 stations which meet the criterion for both 1931-60 and 1961-90.

The result of applying the above methodology was to produce a monthly precipitation time series for the period 1946-1975 in $\mathrm{mm}$ on a $5^{\circ}$ grid, and mean monthly precipitation climatologies for the periods 1931-60 and 1961-90 at the same resolution. Gridbox precipitation estimates were available for $1946-75$ for 698 gridboxes representing $33 \%$ of the surface area of the Earth (Table 2). These gridboxes were largely continental in location, although parts of the central and western Pacific Ocean were represented as well as isolated gridboxes within the Indian and Atlantic Oceans. The gridboxes with the largest numbers of contributing stations (over 20) are concentrated over western USA, western Europe, northeastern Brazil, southeastern Australia, and parts of southern Africa. For the 1931-60 and 1961-90 climatologies, the number of gridboxes fell to 549 and 596 respectively, and gridboxes which possessed mean precipitation estimates for both $30 \mathrm{yr}$ periods numbered 483 (Table 2). This represents $23 \%$ of the surface of the Earth, with poor coverage over the Soviet Union, parts of the Middle East, west central Africa, western Amazonia, and Central America (Fig. 1).

Table 2. Number of precipitation stations and $5^{\circ}$ gridboxes included in each 30 yr period. The criterion for inclusion was at least 25 valid observations in all months. A station or gridbox had to pass the criterion in both periods to be included in the 'Both' subset

\begin{tabular}{|c|c|c|c|c|}
\hline \multicolumn{5}{|c|}{ Stations } \\
\hline Period & \multicolumn{2}{|c|}{$\begin{array}{c}\text { No. of } \\
\text { stations selected }\end{array}$} & $\begin{array}{l}\text { Total no. in } \\
\text { master data set }\end{array}$ & $\begin{array}{c}\% \\
\text { included }\end{array}$ \\
\hline $1946-75$ & & 4404 & & 60 \\
\hline $1931-60$ & & 3658 & & 50 \\
\hline $1961-90$ & & 3317 & & 45 \\
\hline Both & & 2345 & & 32 \\
\hline \multicolumn{5}{|c|}{ Gridboxes } \\
\hline Period & $\begin{array}{c}\text { No. of } 5^{\circ} \\
\text { boxes selected }\end{array}$ & & $\begin{array}{c}\% \\
\text { global boxes }\end{array}$ & $\begin{array}{c}\% \\
\text { surface area }\end{array}$ \\
\hline $1946-75$ & 698 & & 27 & 33 \\
\hline $1931-60$ & 549 & & 21 & 26 \\
\hline $1961-90$ & 596 & & 23 & 27 \\
\hline Both & 483 & & 19 & 23 \\
\hline
\end{tabular}



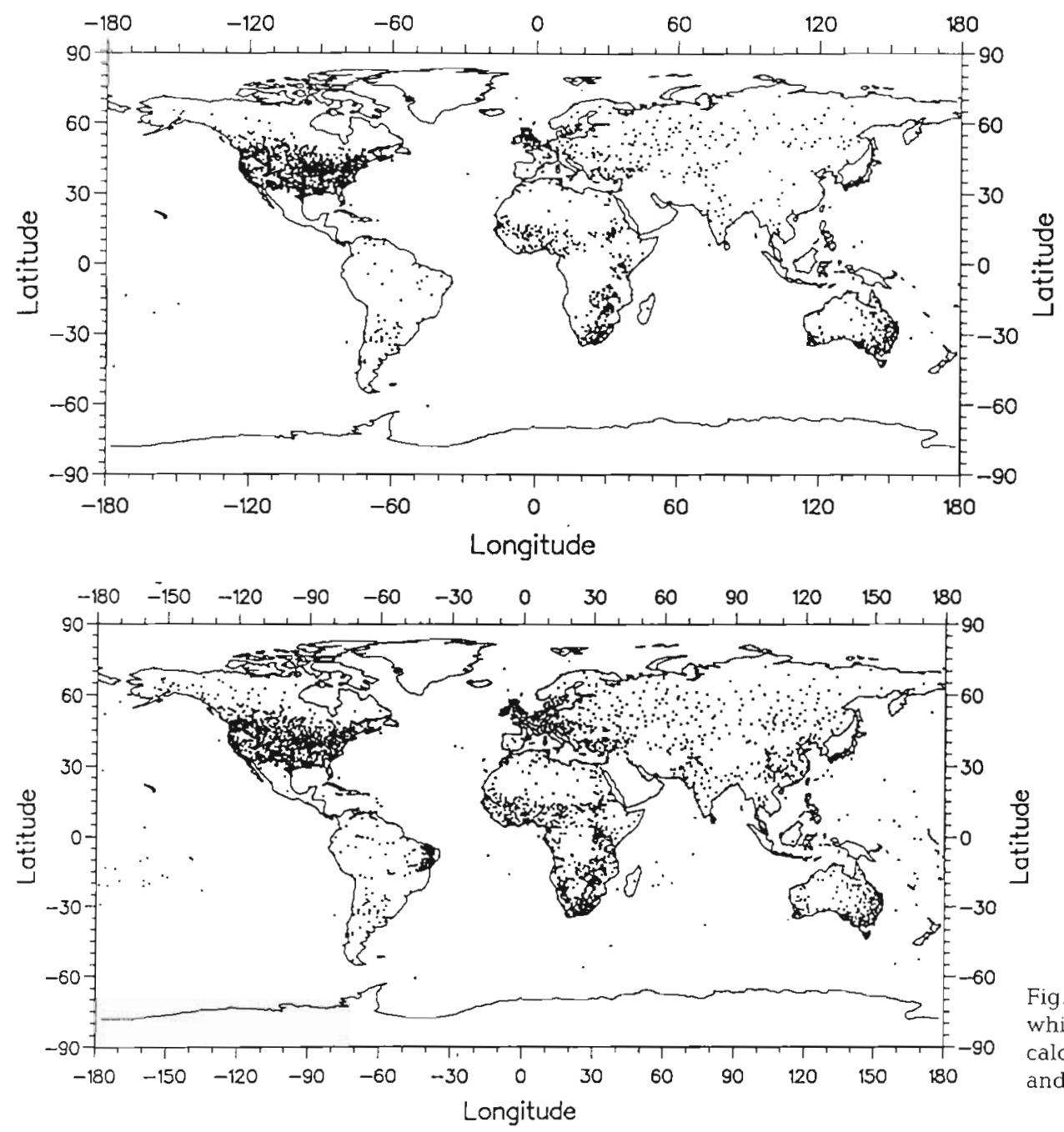

Fig. 2. Distribution of stations for which precipitation means were calculated for (upper) both 1931-60 and 1961-90 and (lower) 1946-75

\section{Global temperature and precipitation change between 1931-60 and 1961-90}

Fig. 3 shows the annual global-and hemisphericmean temperature curves for the period 1854-1991 (Jones \& Wigley 1991). These are derived from the full global gridded temperature data set from which the two $30 \mathrm{yr}$ climatologies were extracted. Globalmean temperature has increased by about $0.45 \pm$ $0.15^{\circ} \mathrm{C}$ since the late 19 th century. The warming has occurred unevenly both in time and space. The 2 periods of greatest warming occurred between 1915 and 1940 and from 1975 to date. A slight global-mean cooling was evident between 1940 and 1970. These trends ensure that the global-mean temperature change between the two 30 yr periods analysed here is very small $\left(1961-90\right.$ is $0.07^{\circ} \mathrm{C}$ warmer than 1931-60); while 1931-60 shows little overall trend in temperatures, the period 1961-90 contains a strong warming trend over the last $15 \mathrm{yr}$. The annual cycle of this global-mean temperature change shows that warming has been greatest in February and March $\left(>0.10^{\circ} \mathrm{C}\right)$ and least between August and October $\left(<0.04^{\circ} \mathrm{C}\right)$ (Fig. 4). The spatial pattern of temperature change between these 2 periods is shown in Fig. 5 for the annual mean, and for the boreal winter (DJF) and summer (JJA) season. The greatest warming, of over $1^{\circ} \mathrm{C}$, is evident over interior parts of the Soviet Union in winter, with similar magnitude winter cooling occurring over eastern North America and high latitudes around Iceland, Scandinavia, and the Arctic coastline of the Soviet Union. Large parts of Africa have cooled slightly on an annual basis, with strongest cooling of between 0.5 and $1.0^{\circ} \mathrm{C}$ over north central Africa in winter.

Using the 483 gridboxes with precipitation estimates for both $30 \mathrm{yr}$ periods, an estimate of the change in global-mean terrestrial precipitation was made. Fig 4 shows the monthly change between 1931-60 and 1961-90 in the resulting global-mean estimates. The 
largest change of $+0.12 \mathrm{~mm} \mathrm{~d}^{-1}$ (approximately $+5 \%$ ) occurred in November while October precipitation decreased by ca $0.04 \mathrm{~mm} \mathrm{~d}^{-1}$ (or $1.6 \%$ ). The change in global-mean annual precipitation was $+0.03 \mathrm{~mm} \mathrm{~d}^{-1}(+10.9 \mathrm{~mm}$ in annual precipitation, or $+1.2 \%$ ). Much larger changes in regional annual and seasonal precipitation, however, have occurred. Fig. 6 shows the percentage change in annual precipitation, and for 2 seasons, DJF and JJA, between 1931-60 and 1961-90. In producing these percentage change plots, gridboxes for which seasonal or annual totals in 1 or both periods were below $8 \mathrm{~mm}$ were treated as zero change boxes; this eliminates the most extreme cases of spuriously large percentage changes in dry regions. The largest regional change has occurred in the African Sahel where annual and summer precipitation has declined by between 10 and $30 \%$ (locally up to $45 \%$ ). Seasonal precipitation increases of between 10 and $30 \%$ have occurred over Western Australia (especially summer, DJF), much of the Soviet Union (especially winter, DJF), eastern Brazil (both JJA and DJF), and the East African coastal region (especially the rainy season, SON; not shown). Although low station densities may potentially give rise to an exaggerated spatial extent of change, at least 2 of the above regions (northeastern Brazil and the African Sahel) possess

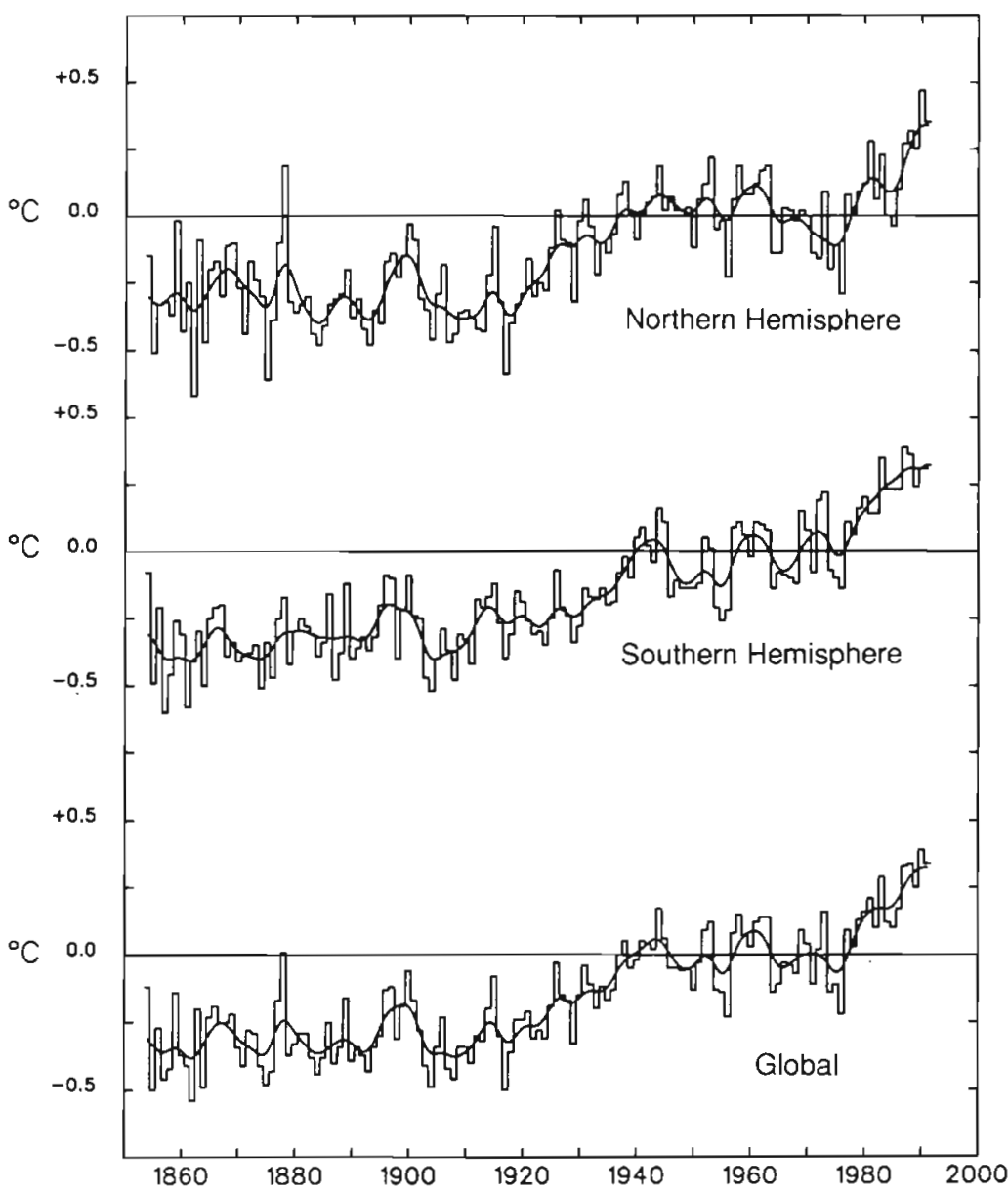

Fig. 3. Global- and hemispheric-mean annual temperature curves for 1854-1991. Smooth lines are 10 yr Gaussian filters. Temperature anomalies are with respect to $1950-79$. These annual global and hemisphere means are derived from the full gridded data set

relatively high station densities.

Interannual variability in regional precipitation anomalies, especially in parts of the tropics, is known to be associated with El Niño/Southern Oscillation (ENSO) events originating in the Pacific Ocean (Ropelewski \& Halpert 1989). It is possible that the two 30 yr periods contained different frequencies of ENSO events and hence the resulting precipitation fields are unduly biased in certain regions. An index of the Southern Oscillation (SOI; Ropelewski \& Jones 1987) was used to compare ENSO events between the 2 periods. The SOI had a mean annual standardised value of -0.04 during 1931-60 ( $\sigma=$ $0.65)$ and $-0.11(\sigma=0.72)$ during 1961-90. Although the negative excursions of the SOI were larger during the latter period, for example the severe ENSO events of 1982/83 and 1986/87, the difference in mean SOI is insignificant and other explanations of the regional precipitation changes noted above are required.

\section{DETERMINATION OF POTENTIAL EVAPOTRANSPIRATION}

A distinction should be made here between potential evapotranspiration (PE) and crop evapotranspiration (CE). PE is the amount of evapotranspiration from an extensive and homogenous cover of vegetation given an unlimited supply of water at the ground surface, while $C E$ is the evapotranspiration from a particular crop and is sometimes derived by adjusting $\mathrm{PE}$ with a crop coefficient which varies with region and the stage of the growing season. In the current analysis we are concerned with PE. There are 3 distinct groups of methods commonly used to determine PE: direct measurement, theoretical formulae and empirical formulae.

Measurement of water loss from a controlled openwater surface gives the best direct estimate of the evaporative demand of the atmosphere. Evaporation pans ( 1 to 2 m diameter) and Piché evaporimeters are 


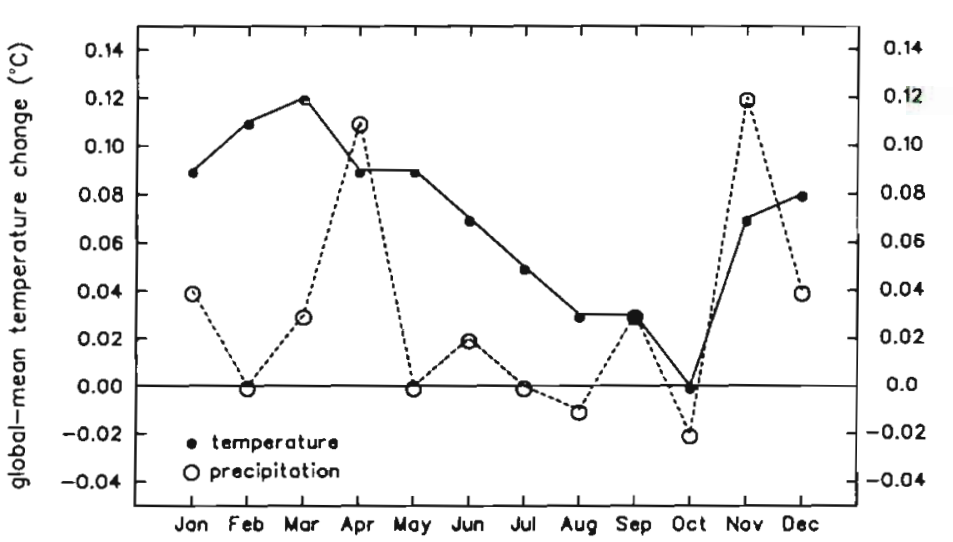

Fig. 4. Monthly global-mean temperature and precipitation change between 1931-60 and 1961-90 derived from the gridded data sets used here. Annual mean temperature change is $+0.07^{\circ} \mathrm{C}$ and annual mean precipitation change is $+0.03 \mathrm{~mm} \mathrm{~d}^{-1}$ (or $+1.2 \%$ ). Global-mean temperature is based on 1384 land and ocean $5^{\circ}$ gridboxes and global-mean precipitation on 483 terrestrial $5^{\circ}$ gridboxes

used for this purpose at meteorological stations. These direct measurements have drawbacks. For example, evaporation varies with pan size, water depth, and exposure, and, especially in arid and semi-arid areas, advection effects lead to an overestimation of evaporation using pans (Jackson 1989). Lysimeters provide the equivalent direct measurement of PE from standard land cover types. The paucity of long station time series of these standard evaporation measurements render such sources of $P E$ estimates impractical on a global scale.

Many attempts have been made to produce satisfactory theoretically-based formulae for the estimation of PE. From physical principles there are 4 main meteorological factors which will determine PE: solar radiation, wind velocity, relative humidity and temperature. The most satisfactory formula for estimating $P E$ will incorporate all these factors. The earliest detailed scientific assessment of $P E$, and still the starting point for any theoretical estimate of PE, was made by H. L. Penman in the late 1940s and early 1950s (e.g. Penman 1948). His theory is based on 2 requirements which must be met if continuous evaporation is to occur: first, there must be a supply of energy to provide the latent heat of vaporisation and, second, there must

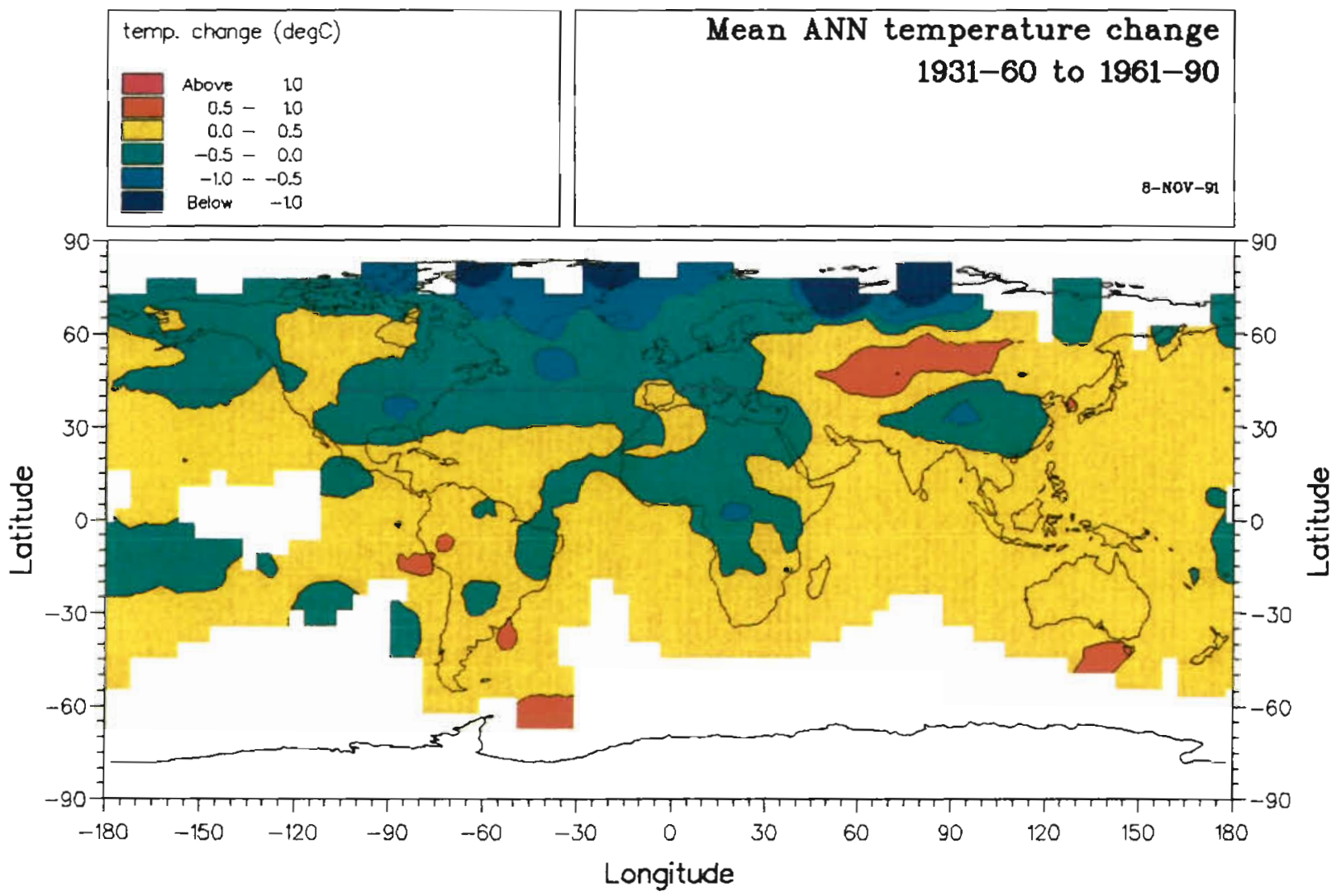

Fig. 5. Temperature change $\left({ }^{\circ} \mathrm{C}\right)$ between $1931-60$ and $1961-90$ derived from the $5^{\circ}$ gridded data. ANN: annual; DJF: boreal winter; JJA: boreal summer. Interpolation and contouring performed by UNIRAS Graphics, Version 6.0 

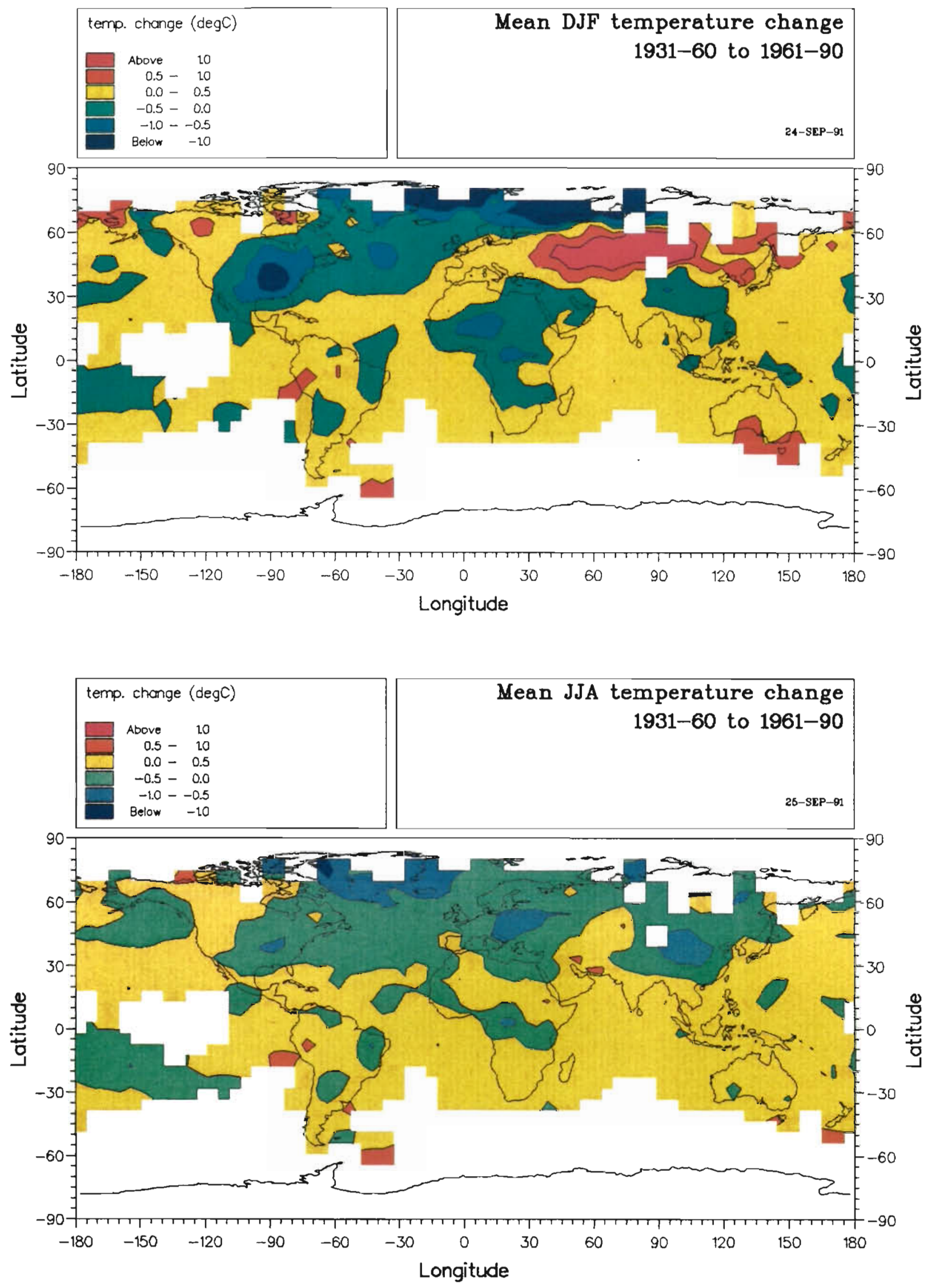
be some mechanism for removing the vapour once produced. Numerous variations of Penman's general equation have been proposed by different authors intent on either specific regional or systematic applications. For example, the Penman-Monteith form of the equation incorporates a canopy or surface resistance term to characterise water transfer between stomata and the atmosphere (Monteith 1973). A simplification of the Penman equation has been proposed by Makkink (KNMI 1988) which makes PE a function of just 2 variables, temperature and global radiation. This has been used by the Food and Agricultural Organisation (FAO) in their crop water requirement studies. Makkink's equation is a simplified version of Penman's equation, adapted for agricultural plants (particularly northern European temperate grassland).

One major disadvantage of the Penman method is the large number of meteorological variables required in the calculation. Such variables are not available at many meteorological stations and are certainly not available as monthly time series over 60 yr for a sufficient number of global stations to derive 2 independent global PE surfaces. Alternative simpler formulae have therefore been constructed which rely on the empirical relationship between measured PE and certain meteorological variables. Two of these are the formulae of Thornthwaite (1948) and Blaney \& Criddle (1950) (the latter estimates $\mathrm{CE}$ ). Since such relationships are often derived from limited regions, the formulae may be less satisfactory when used elsewhere. For example, Thornthwaite's method was developed in the USA and is known to underestimate PE in arid and semi-arid months or regions, and to overestimate PE in cold climates (Mather \& Ambroziak 1986). For the analysis described here it was decided to generate mean monthly global PE surfaces, gridded at $5^{\circ}$ resolution, using the Thornthwaite method. This required only monthly mean temperatures, and, in contrast to the Blaney and Criddle method, there was no necessity to make assumptions about global vegetation cover and its change between 1931-60 and 1961-90.

\section{Application of Thornthwaite method}

The Thornthwaite formula requires only 2 variables for its calculation, monthly mean temperature over the annual cycle and the average number of hours

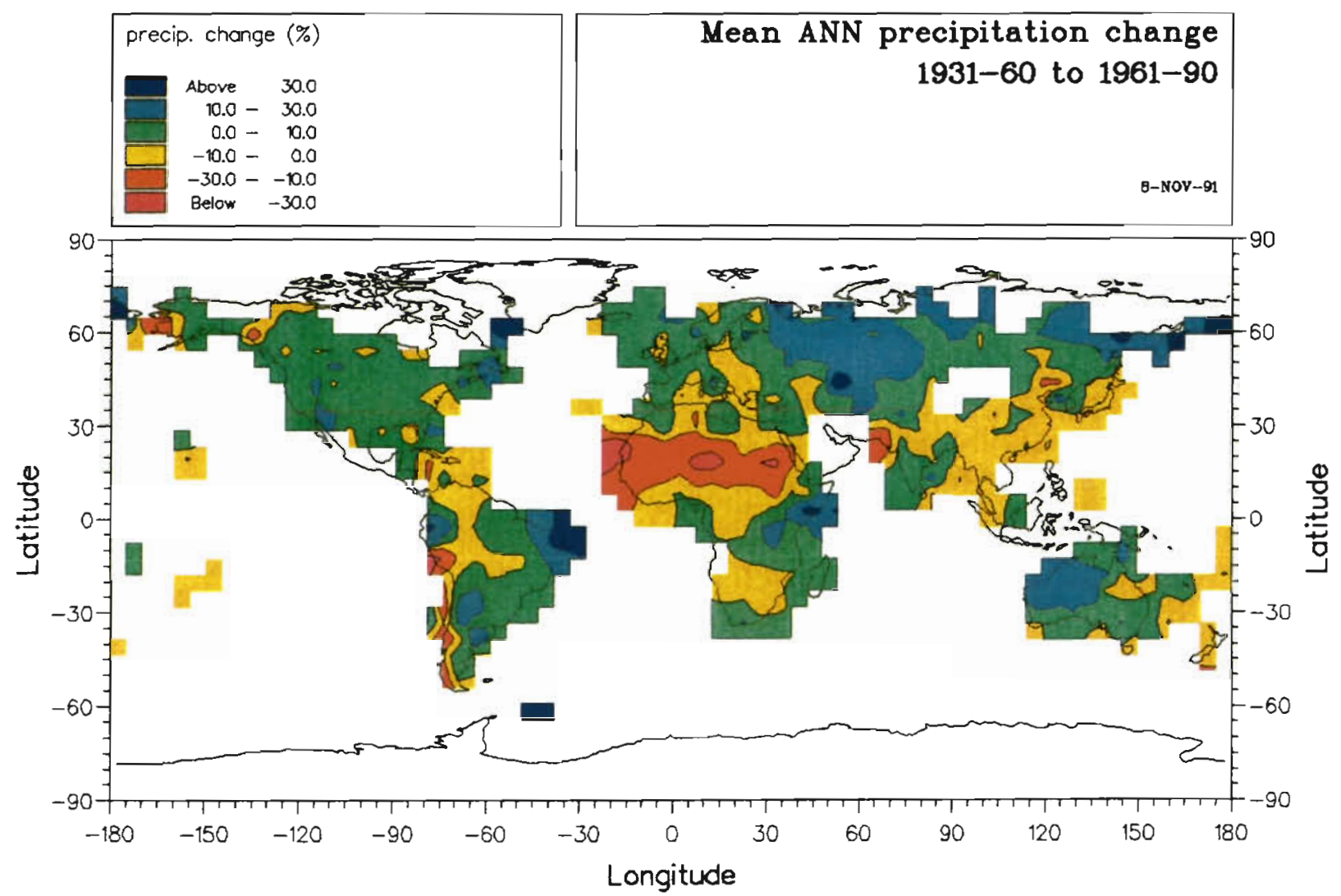

Fig. 6. Precipitation change between 1931-60 and 1961-90 (percentage of 1931-60) derived from the $5^{\circ}$ gridded data. ANN: annual; DJF: boreal winter; JJA: boreal summer. Interpolation and contouring performed by UNIRAS Graphics, Version 6.0 

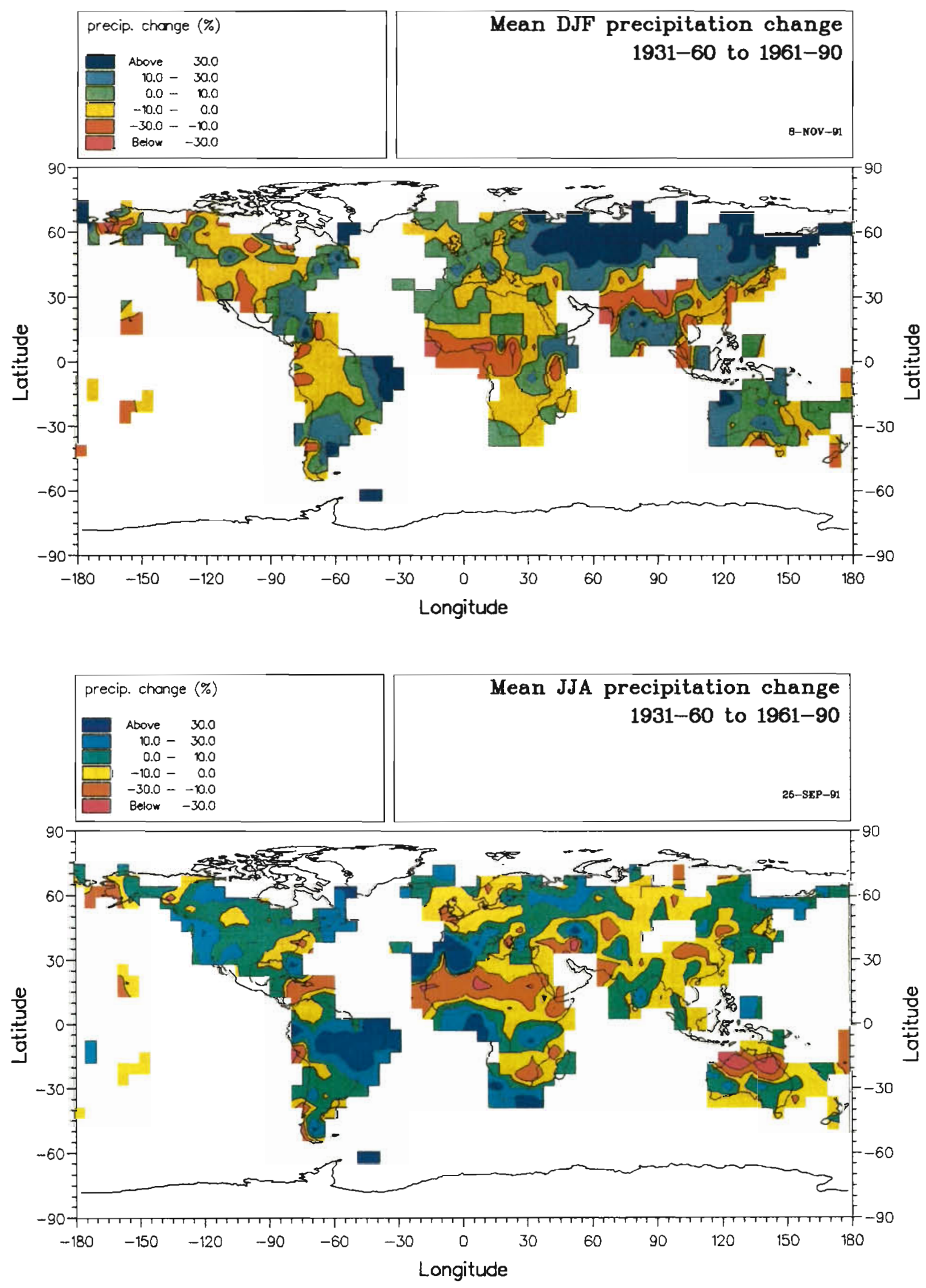
between sunrise and sunset in the month. An annual heat index representing the overall warmth or coolness of the climate was calculated for each gridbox for 1931-60 and 1961-90 from the mean monthly temperatures. The average number of daylight hours for the midpoint of each gridbox was extracted from tables. For latitudes greater than $50^{\circ} \mathrm{N}$ or $\mathrm{S}$ the $47.5^{\circ}$ daylength value was used as recommended by Thornthwaite (1948); this allows for the fact that energy receipt at high latitudes is increasingly small despite long daylight hours. Where the mean monthly temperature exceeded $26.5^{\circ} \mathrm{C}, \mathrm{PE}$ is determined directly from temperature, i.e. the relationship between temperature and PE in very hot months is independent of the overall warmth or coolness of the annual climate. Where the mean monthly temperature was below zero, $\mathrm{PE}$ was also zero, implying insufficient energy to evaporate water.

One additional qualification not identified explicitly by Thornthwaite was introduced into the scheme. In very cold annual climates, with temperatures in most months below zero and 1 or 2 mo with small positive temperatures, the annual heat index takes on a very small value. Very large values of PE result. Since the Thornthwaite method was not designed for very cold climates, a cutoff was applied so that for a gridbox with an annual heat index less than 10 (generally northwards of about $65^{\circ} \mathrm{N}$ ) no PE estimate was made for any month. This affected cold regions which were of limited interest in the UNEP/GEMS study.

\section{Evaluation of gridded mean PE}

Applying the above method to the mean gridded temperatures resulted in mean monthly PE estimates for the 2 periods 1931-60 and 1961-90. Gridded PE estimates for both time periods cover about $64 \%$ of the land surface of the Earth.

How reliable are these PE estimates? It was stated earlier that empirical formulae such as Thornthwaite's have been developed in specific regions and are not necessarily transferable to regions with very different climatic regimes. Thornthwaite's method was originally developed for the United States, thus it is expected that the gridded $P E$ estimates for this region will be most representative of 'true' PE. Fig. $7 \mathrm{com}$ pares measured average annual PE, standardised to 1930, based on 3500 U.S. Weather Bureau stations (Thornthwaite 1948) with average annual PE for 1931-60 using our adaptation of the Thornthwaite method applied to the mean gridded temperature data. The agreement, if the complications of the Rocky Mountains region are ignored, is generally very good. Although the United States covers a wide range of

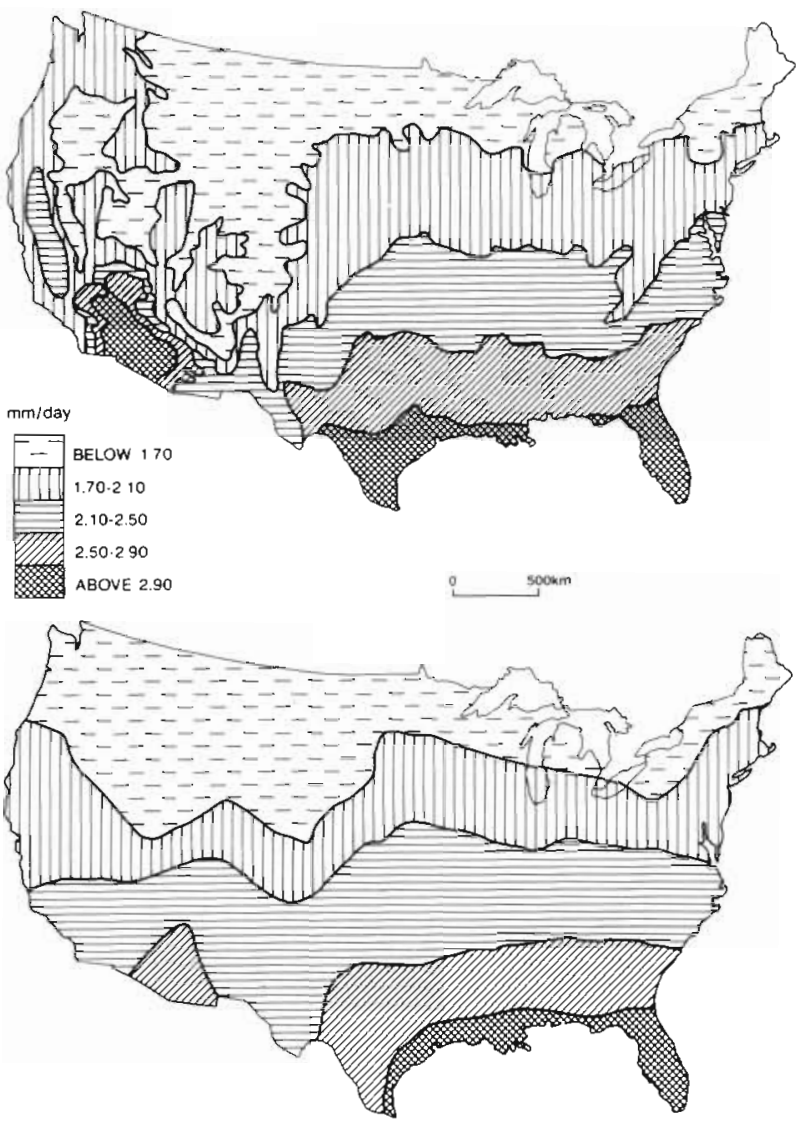

Fig. 7. Mean annual PE over the USA (upper) from measured pan estimates standardised to 1930 (source: Thornthwaite 1948) and (lower) from the Thornthwaite method used here and applied to gridded mean temperatures for 1931-60

climatic regimes, this is no guarantee that the Thornthwaite method works well outside the USA. Kumar et al. (1987) compared Penman and Thornthwaite methods for estimating PE over India and showed that although annual PE totals are similar, Thornthwaite produces lower PEs than Penman in the dry season and higher PEs than Penman in the wet season. For such reasons, the gridded PE estimates were evaluated for 2 regions outside the USA: Europe and Sudan.

Mean monthly gridded PE for 1961-90 derived for 5 gridboxes in western Europe using the Thornthwaite method were compared with PE estimates derived for individual stations using 4 alternative theoretical formulae. These stations possessed complete meteorological data for the period 1955-88. The 4 alternative formulae were: the original Penman; a simplification of Penman by Makkink; Blaney and Criddle; and the standard Thornthwaite method using the station mean temperatures instead of the gridded mean temperatures. The individual station PE estimates were then averaged by gridbox to produce mean PE estimates 
Table 3. European gridboxes used to evaluate gridded Thornthwaite PE estimates for $1961-90$ and the number of stations used in the evaluation. Mean altitudes are provided for comparison. Gridbox mean altitudes are derived from a $0.5^{\circ}$ digital terrain model

\begin{tabular}{|lllccc|}
\hline Box number & $\begin{array}{c}\text { Latitude } \\
\left({ }^{\circ} \mathrm{N}\right)\end{array}$ & Region & $\begin{array}{c}\text { No. of } \\
\text { stations }\end{array}$ & $\begin{array}{c}\text { Mean altitude } \\
\text { of stations (m) }\end{array}$ & $\begin{array}{c}\text { Mean altitude } \\
\text { of gridbox (m) }\end{array}$ \\
\hline 1835 & 37.5 & Southern Portugal & 2 & 273 & 153 \\
1909 & 42.5 & Southern France & 1 & 152 & 258 \\
1981 & 47.5 & Central France & 4 & 188 & 269 \\
2052 & 52.5 & England & 3 & 66 & 122 \\
2124 & 57.5 & Scotland & 1 & 35 & 95 \\
\hline
\end{tabular}

comparable to the previously calculated gridded PE from Thornthwaite. The boxes and station numbers are shown in Table 3 and the annual cycle of mean PE is plotted for these gridboxes in Fig. 8.

The annual cycle of PE is well-captured by the gridded Thornthwaite PE estimates for all 5 European gridboxes. In 4 of the boxes, gridded Thornthwaite PE produces estimates which are very similar to the Blaney and Criddle method, consistently lower than the standard Penman method and consistently higher than Makkink's simplification of Penman's method. In these 4 boxes the gridded Thornthwaite PE is in general slightly lower than Thornthwaite PE derived from station temperatures - this slight difference can be explained by the difference in the mean elevations and hence temperatures. The exception is the southern Portugal box where gridded Thornthwaite PE is lower than that the other 4 methods in summer, although following the same pattern as above in winter. The explanation for this probably lies in the more semi-arid nature of the climatic regime and in the elevation of the 2 stations used for the evaluation (mean $273 \mathrm{~m}$; Table 3 ). In summer over interior Portugal, an inverse lapse rate is likely so that the station temperatures, and hence PE, are somewhat
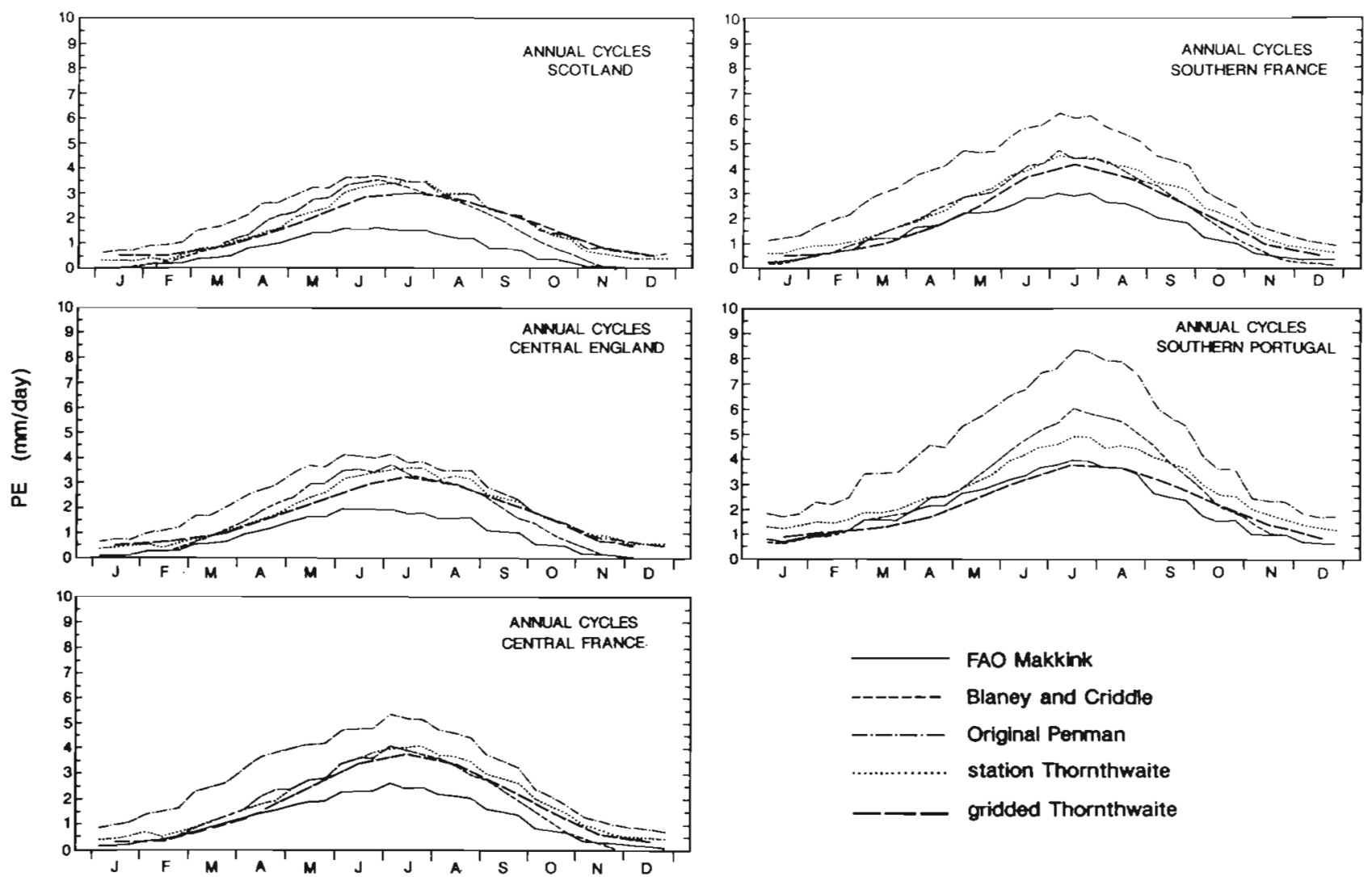

Fig. 8. Mean monthly PE for 1955-88 derived from 5 different formulae for 5 European gridboxes. See text for an explanation of formulae 
higher than the mean gridbox temperature which used a gridbox elevation of only $153 \mathrm{~m}$ (derived from the digital terrain model) and assumed a standard lapse rate.

Three gridboxes in Sudan were selected for evaluation. Mean monthly PE estimates for 1951-80 based on the Penman method (Awadulla 1983) were available for numerous stations in Sudan. For each gridbox 3 stations were selected and the Penman PE estimates averaged. Table 4 shows these station numbers and Fig. 9 shows the comparison of the mean annual PE cycles. It is clear from Fig. 9 that as the region or season becomes increasingly arid so Thornthwaite's method increasingly underestimates PE compared to the Penman method. This confirms the finding of Kumar et al. (1987) for India. For southern Sudan (a humid climate), this underestimation is less than $10 \%$ in the wet season and rises to $25 \%$ in the dry season. In semi-arid northern Sudan, the underestimate is $25 \%$ in the wet season and rises to $75 \%$ in the dry season. This large difference in the 2 methods arises because the Thornthwaite method fails to allow for variations in vapour pressure. In arid regions or seasons, very low vapour pressures occur, thus increasing the potential evaporating power of the atmosphere. Penman's method allows for this and hence generates much larger PE estimates in these cases.

From the European evaluation, we conclude that for temperate latitudes the application of the Thornthwaite method to the global temperature data set produces gridded PE estimated very similar to the Blaney and Criddle method and consistently smaller by between 5 and $40 \%$ than the original Penman method. These latter differences are smallest in cooler climates and seasons. For arid regions and seasons, the underestimate of PE represents a systematic bias in the Thornthwaite method. When calculating $\mathrm{HI}$ this will lead to rather favourable ratios for arid regions and seasons. Since this bias is systematic, when assessing the change in humidity from 1931-60 to $1961-90$ this is not too serious a handicap. Hence the calculation of change in annual PE between 1931-60 and 1961-90 discussed later is not adversely affected. Interpretation of the absolute gridded humidity index values must, however, take this bias into consideration and we therefore derived an adjustment factor for Thornthwaite PE.

\section{An empirically-derived adjustment factor for annual Thornthwaite PE estimates}

How serious is this problem of systematic bias in the Thornthwaite estimates of PE? One solution is to adjust empirically the Thornthwaite PE estimates to agree more closely with Penman PE estimates (although the Penman method itself only provides an estimate of PE, albeit a more physically based one). Two detailed regional PE data sets were available to us for derivation of an appropriate adjustment factor. For Sudan, mean monthly PE for 1951-1980 calculated using the Penman method were available for 48 stations (Awadulla 1983) ranging in annual precipitation from 0 to over $1400 \mathrm{~mm}$. For Europe, mean monthly PE for 1955-1988 calculated using the Penman method were available for 61 stations ranging in annual precipitation from 350 to $1400 \mathrm{~mm}$. In both data sets, mean monthly temperature was also available for all stations and hence monthly and annual PE calculated using Thornthwaite's method could be obtained.

Our initial approach used annual $P_{\mathrm{t}}$ (Thornthwaite's PE) to derive PE $_{p}$ (Penman's PE). We performed some initial experiments using monthly data to derive monthly adjustment factors and summed the adjusted monthly $P E_{t}$ to obtain adjusted annual $P E_{t}$. This approach proved to be of lesser value, and considerably more complex, than using annual data alone. Thus we developed the following model:

$$
P E_{p}=f\left(\mathrm{PE}_{\mathrm{t}}\right)=a \mathrm{PE}_{\mathrm{t}}+c
$$

where $\mathrm{PE}_{\mathrm{p}}=$ annual Penman $\mathrm{PE} ; \mathrm{PE}_{\mathrm{t}}=$ annual Thornthwaite $\mathrm{PE}$; and $a$ and $c$ are regression coefficients.

Five different regression equations were constructed; the coefficients and results are summarised in Table 5 and in Fig. 10. Apart from Eq. (5), these equations all state that the underestimation of PE by the Thornthwaite method increases with mean annual PE. Eq. (5) (based on Sudan data alone) shows, however, that this simple adjustment does not necessarily hold for all regimes.

In Eq. (1) in Table 5, the full data set of 109 stations was used both as the training set and for verification. Eqs. (2) and (3) were derived by randomly dividing this

Table 4. Sudan gridboxes used to evaluate gridded Thornthwaite PE estimates for $1961-90$ and the number of stations used in the evaluation. Mean elevations are provided for comparison. Gridbox mean altitudes are derived from a $0.5^{\circ}$ digital terrain model

\begin{tabular}{|cclccc|}
\hline Box number & $\begin{array}{c}\text { Latitude } \\
\left({ }^{\circ} \mathrm{N}\right)\end{array}$ & Region & $\begin{array}{c}\text { No. of } \\
\text { stations }\end{array}$ & $\begin{array}{c}\text { Mean altitude } \\
\text { of stations (m) }\end{array}$ & $\begin{array}{c}\text { Mean altitude } \\
\text { of gridbox (m) }\end{array}$ \\
\hline 1411 & 7.5 & Southern Sudan & 3 & 407 & 530 \\
1483 & 12.5 & Central Sudan & 3 & 460 & 490 \\
1555 & 17.5 & Northern Sudan & 3 & 310 & 420 \\
\hline
\end{tabular}



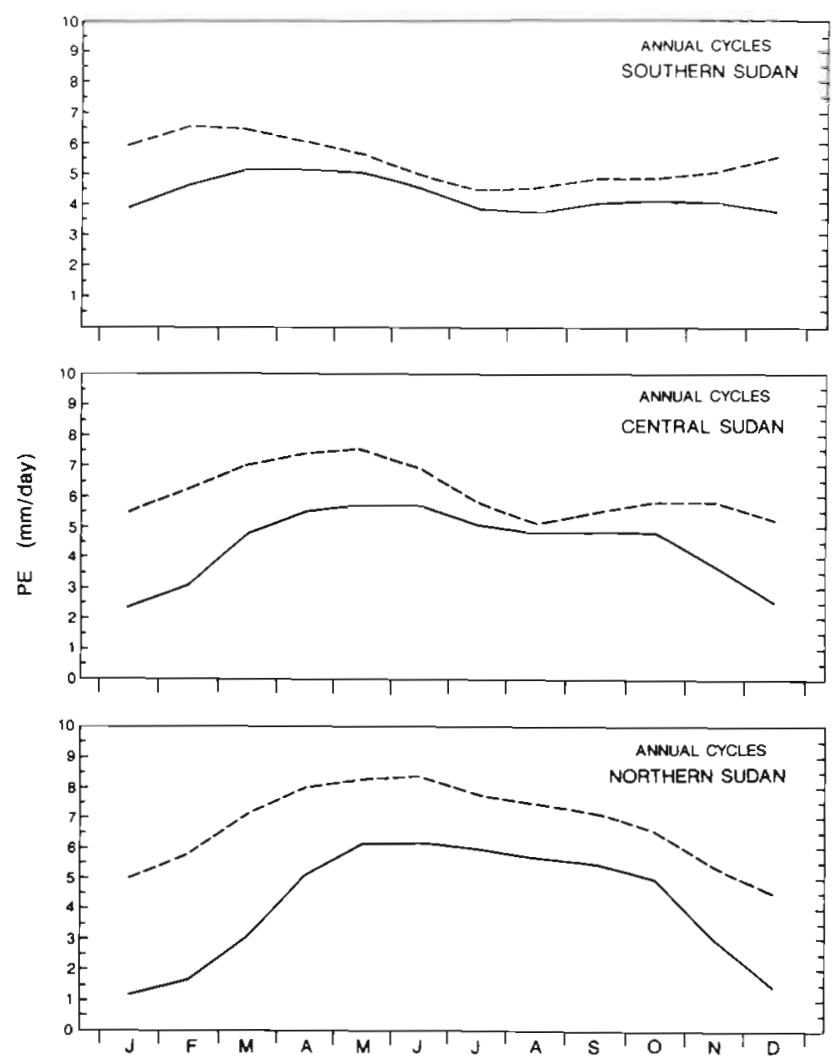

Fig. 9. Mean monthly PE using the Penman method (---) and the unadjusted Thornthwaite method (-) for 3 Sudan gridboxes. The Penman mean is based on $1951-80$ and the Thornthwaite mean on 1961-90 [source for Penman PE estimates: Awadulla (1983)]

data set into 2 subsets, and using the subsets separately for training and verification. Very similar models resulted in all 3 cases. To test further the stability of this relationship, Eq. (4) was derived from the European data set alone and tested on the Sudan data and vice versa for Eq. (5). While the European model performs fairly well in Sudan, the Sudanese model differs considerably from the previous 4 , has little explanatory power $(20.1 \%)$, and performs very poorly when applied to Europe (Table 5).
In view of the poor result obtained with the Sudanese model, mean annual precipitation was introduced as a second predictor of $P E_{\mathrm{p}}$. Since the underestimation of PE by Thornthwaite's method is greatest in dry regions and seasons, an improved adjustment factor may be obtained if precipitation (an indicator of the aridity of the climate and hence the likely magnitude of the underestimation of $P E_{t}$ ) is included. Thus:

$$
P E_{p}=f\left(P E_{t}, P\right)=a P E_{t}+b P+c
$$

where $\mathrm{P}=$ mean annual precipitation and $a, b$ and $c$ are regression coefficients.

Three equations were developed using the full data set (note that only 30 of the 61 European stations with $\mathrm{PE}_{\mathrm{p}}$ possessed mean annual precipitation), the European data set alone, and the Sudan data set alone. The resulting equations and statistics are shown in Table 6 and Fig. 10. The adjusted $\mathrm{R}^{2}$ of the full data set equation (Eq. 6) is slightly greater than before and the resulting reduction in the rms error is larger, both for the full and European data sets. Although applying the Sudan equation (Eq. 8) to Europe still produces meaningless results, with an adjustment $\mathrm{R}^{2}$ of $74.2 \%$ it is now at least internally consistent (cf. $20.1 \%$ for Eq. 5). In view of the high $\mathrm{R}^{2}$ of Eq. (6), the large reduction in rms error which results, and the adequacy of the model form for Sudan [(i.e. $\left.\mathrm{PE}_{\mathrm{p}}=f\left(\mathrm{PE}_{\mathrm{t}}, \mathrm{P}\right)\right]$, Eq. (6) was adopted as a global adjustment factor for annual $P E_{t}$ estimates.

As a test of the adjustment factor, Eq. (6) was applied to the global field of gridded mean 1950-79 annual Thornthwaite PE, using the 1946-75 mean annual precipitation. The difference between the unadjusted and adjusted annual PE fields for 1950-79 indicates that annual precipitation is the strongest control on the magnitude of the adjustment (not shown). Where annual precipitation is greater than about $2000 \mathrm{~mm}$, there is virtually no change to $\mathrm{PE}_{1}$ (e.g. Amazonia, southeast Asia). As annual precipitation decreases, the size of the adjustment (in percentage terms) increases. With precipitation less than $500 \mathrm{~mm}$, percentage ad-

Table 5. Details of the regression models developed using annual $P E_{t}$ (Thornthwaite $P E$ ) as the only predictor for $P E_{p}$ (Penman $P E$ ). Root mean square (rms) error of unadjusted and adjusted annual $\mathrm{PE}_{\mathrm{q}}$ of the verification set is calculated as the percentage of mean annual $\mathrm{PE}_{\mathrm{p}}$ and quantifies the improvement which results from applying each respective model

\begin{tabular}{|c|c|c|c|c|c|c|c|c|}
\hline \multirow[t]{2}{*}{ Model } & \multirow[t]{2}{*}{ Equation } & \multirow{2}{*}{$\begin{array}{l}\text { Training } \\
\text { set size }\end{array}$} & \multirow{2}{*}{$\begin{array}{l}\text { Verification } \\
\text { set size }\end{array}$} & \multicolumn{2}{|c|}{ Coefficients } & \multirow{2}{*}{$\begin{array}{l}\text { Model } \\
\mathrm{R}^{2}\end{array}$} & \multirow{2}{*}{\multicolumn{2}{|c|}{$\begin{array}{c}\text { Verification set } \\
\text { Ims error }\end{array}$}} \\
\hline & & & & $a$ & $c$ & & & \\
\hline All & (1) & 109 & 109 & 1.47 & -250 & $91.1 \%$ & $28.0 \%$ & $15.1 \%$ \\
\hline $\mathrm{Al} / 2$ & (2) & 54 & 55 & 1.50 & -279 & $90.9 \%$ & $30.4 \%$ & $15.2 \%$ \\
\hline All/2 & (3) & 55 & 54 & 1.45 & -227 & $91.1 \%$ & $29.6 \%$ & $15.2 \%$ \\
\hline European & (4) & 48 & 61 & 1.48 & -276 & $85.5 \%$ & $28.0 \%$ & $13.7 \%$ \\
\hline Sudanese & (5) & 61 & 48 & 0.73 & 986 & $20.1 \%$ & $19.3 \%$ & $92.3 \%$ \\
\hline
\end{tabular}


regressing on ALL dota
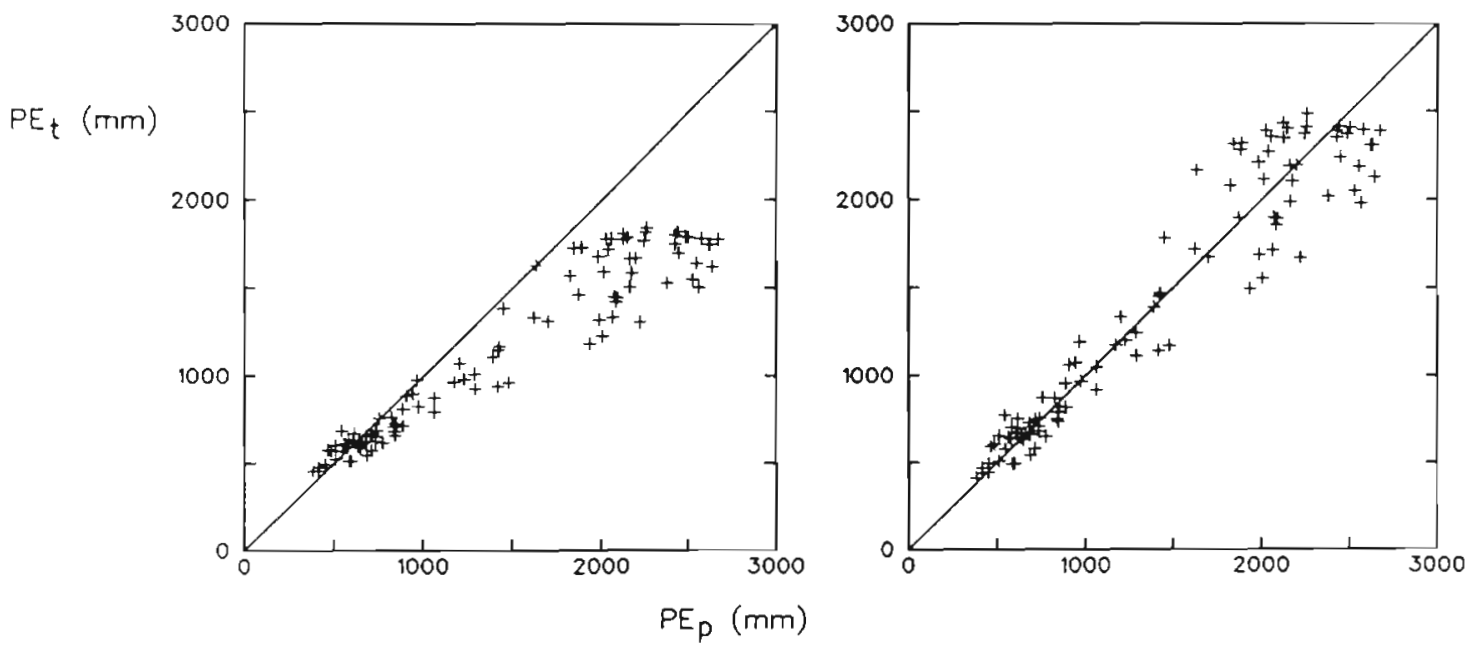

regressing on ALL data, adjusted by precipitation
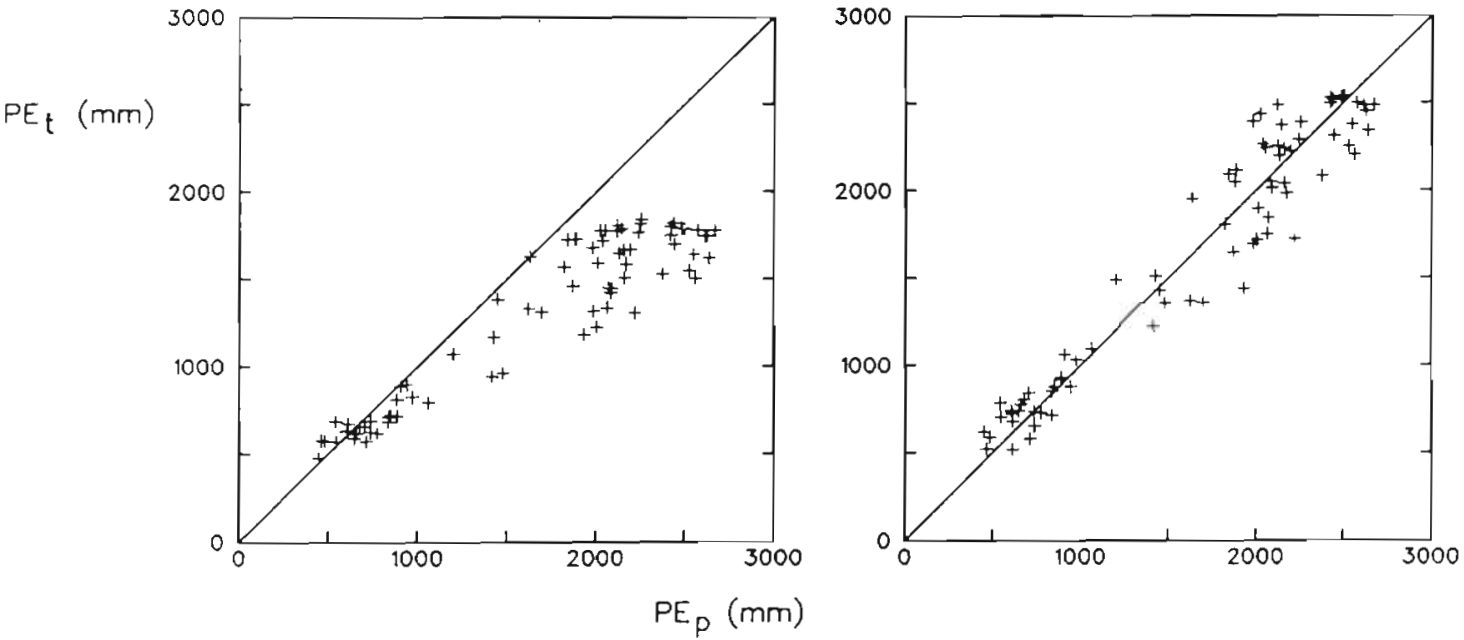

Fig. 10. Plots of unadjusted (left) and adjusted (right) mean annual Thornthwaite PE vs mean annual Penman PE using (upper) Eq. (1) on all 109 stations in the combined Europe and Sudan data set and (lower) Eq. (6) on all 78 stations in the combined Europe and Sudan data set. In the upper model, root mean square error reduces from 28.0 to $15.1 \%$ and in the lower model from 29.6 to $11.9 \%$

Table 6. Details of the regression models developed using annual $\mathrm{PE}_{\iota}$ (Thornthwaite PE) and precipitation as predictor of $\mathrm{PE}_{\mathrm{p}}$ (Penman PE). Root mean square (rms) error of unadjusted and adjusted annual $P E_{1}$ of the verification set is defined as the percentage of mean annual $\mathrm{PE}_{\mathrm{p}}$ and quantifies the improvement which results from applying each respective model

\begin{tabular}{|c|c|c|c|c|c|c|c|c|c|}
\hline \multirow[t]{3}{*}{ Model } & \multirow[t]{3}{*}{ Equation } & \multirow{3}{*}{$\begin{array}{l}\text { Training } \\
\text { set size }\end{array}$} & \multirow{3}{*}{$\begin{array}{l}\text { Verification } \\
\text { set size }\end{array}$} & \multicolumn{3}{|c|}{ Model coefficients } & \multirow{3}{*}{$\underset{\mathrm{R}^{2}}{\text { Model }}$} & \multirow{2}{*}{\multicolumn{2}{|c|}{$\begin{array}{l}\text { Verification set } \\
\text { rms error }\end{array}$}} \\
\hline & & & & \multirow[t]{2}{*}{ a } & \multirow[t]{2}{*}{$b$} & \multirow[t]{2}{*}{$c$} & & & \\
\hline & & & & & & & & Unadj. & Adj. \\
\hline All & (6) & 78 & 78 & 1.30 & -0.43 & 246 & $91.1 \%$ & $29.6 \%$ & $11.9 \%$ \\
\hline European & (7) & 30 & 48 & 1.45 & -0.23 & -64 & $84.7 \%$ & $28.0 \%$ & $11.8 \%$ \\
\hline Sudan & (8) & 48 & 30 & 0.27 & -0.58 & 2027 & $72.9 \%$ & $20.6 \%$ & $121.6 \%$ \\
\hline
\end{tabular}


justment can amount to between +30 and $70 \%$. This is quite plausible in hot arid and semi-arid climates (e.g. Saharan margins, Australia) but less so in cold climates (e.g. Soviet and Canadian tundra). Indeed, the $\mathrm{PE}_{t}$ adjustment should be treated sceptically in these latter regions. Comparison of our adjusted PE with the maps of annual Thornthwaite and Penman PE over India prepared by Kumar et al. (1987) suggests that the adjustment factor has slightly overcompensated Thornthwaite PE in the more humid southerly parts of the sub-continent, but has performed well in the drier northwestern region of the sub-continent where the adjusted Thornthwaite and Penman PE estimates are now in better agreement.

\section{Global PE change from 1931-60 and 1961-90}

Since the adjusted Thornthwaite method of estimating PE is closely dependent on mean temperature, the PE change over the two 30 yr periods will largely follow the change in mean temperature - a very slight annual global-mean warming $\left(+0.07^{\circ} \mathrm{C}\right)$, biased slightly to the January to June half-year, and more pronounced in the Southern Hemisphere. Fig. 11 shows the percentage change in mean annual PE. Global-mean annual PE has increased by $0.76 \%$ for $9 \mathrm{~mm}$ ) with changes in gridbox PE generally less than $3 \%$. The main exceptions to this are larger increases over the South Atlantic, interior Brazil, and, in boreal winter, over Europe and the Mediterranean (not shown). Large decreases in PE are evident over central Africa, interior China, and, in boreal winter, over eastern USA and the north Atlantic, and, in summer, over eastern Europe and the south Pacific.

\section{DETERMINATION OF THE HUMIDITY INDEX}

The ratio precipitation/potential evapotranspiration (P/PE) is a convenient index of moisture availability used by FAO/UNESCO/WMO in the 1977 assessment of desertification. This index is in effect the same as Thornthwaite's 'moisture index' (Thornthwaite 1948), although he used the index in percentage rather than ratio form. We term the ratio $\mathrm{P} / \mathrm{PE}$ as a humidity index (HI) which can be calculated for each respective time period. A value of 1.0 indicates that precipitation and potential water loss through evapotranspiration are equal. Values above 1.0 indicate a potential water

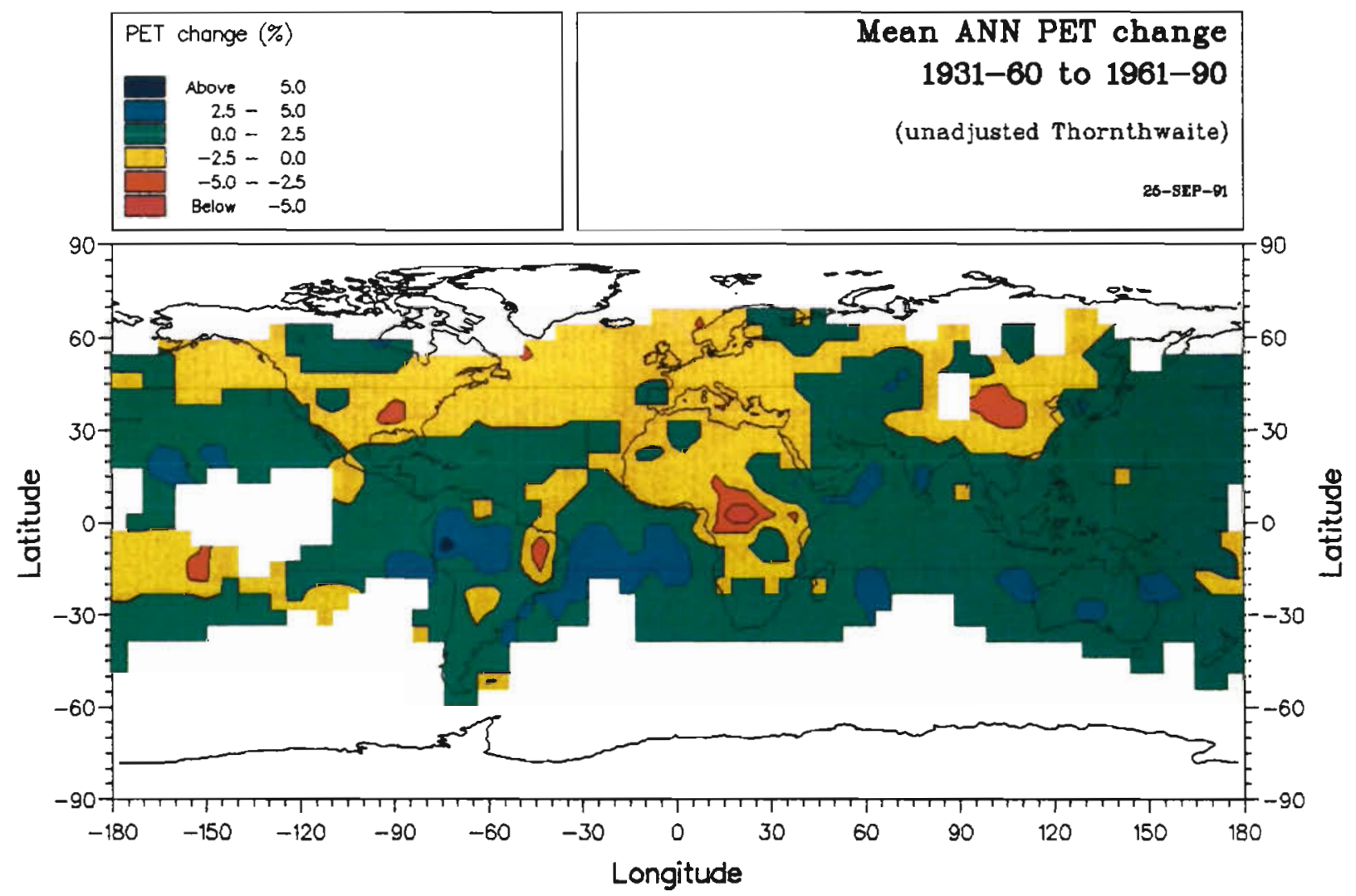

Fig. 11. Change in mean annual PE from 1931-60 to 1961-90 (percentage of 1931-60) where PE is calculated using unadjusted Thornthwaite. Interpolation and contouring performed by UNIRAS Graphics, Version 6.0 
surplus and values below 1.0 a potential water deficit. Using the humidity index, it is possible [following numerous others, e.g. Thornthwaite (1931), Köppen (1936), etc.] to develop a climatic classification, with different climate zones being identified on the basis of the monthly, seasonal, or annual humidity index (note that only annual values of the index can be calculated using our adjusted Thornthwaite PE). In Fig. 12, the annual $\mathrm{HI}$ for 1931-60 is plotted with boundaries at $0.05,0.2,0.5$, and 0.65 . These boundaries were adopted by UNEP/GEMS for the 1992 assessment and separated 'hyper-arid', 'arid', 'semi-arid', 'dry subhumid', and 'humid' moisture zones. The major desert regions of the world (west central Australia, the Middle East, the Sahara, southwestern Africa, and the west coast of South America) roughly correspond to the areas with an annual HI of less than 0.2.

The annual $\mathrm{HI}$ was calculated for both time periods for those gridboxes possessing both precipitation and $\mathrm{PE}$ estimates. By differencing the respective annual humidity indices for 1931-60 and 1961-90 it is possible to map the change in potential water surplus or deficit that has occurred over the last 60 yr. Fig. 13 shows the pattern of such change by mapping the regions with increases or decreases in the HI. Increases occurred over equatorial Africa, western Australia, western Europe, southern USA, and southeastern South America, and decreases occurred over both northern and southern Africa, large parts of southeast Asia, western South America, and parts of eastern Australia

\section{DISCUSSION AND CONCLUSIONS}

The annual HI constructed here can be used to estimate changes in the areas of dryland regions over the last 60 yr. As an example, Table 7 provides area estimates for continental Africa for the 5 moisture zones used in the 1992 UNEP/GEMS desertification assessment. A general desiccation of Africa has occurred with an increase of 50 million hectares of hyper-arid $(\mathrm{HI}<0.05)$ land and the humid $(\mathrm{HI}>0.65)$ zone losing 26 million hectares. Overall, $63 \%$ of the continent experienced a reduction in the $\mathrm{HI}$ and $7.3 \%$ of the land area moved into a drier moisture zone. Most of these transitions were from semi-arid to arid and from arid to hyper-arid, particularly in tropical north Africa. Be-

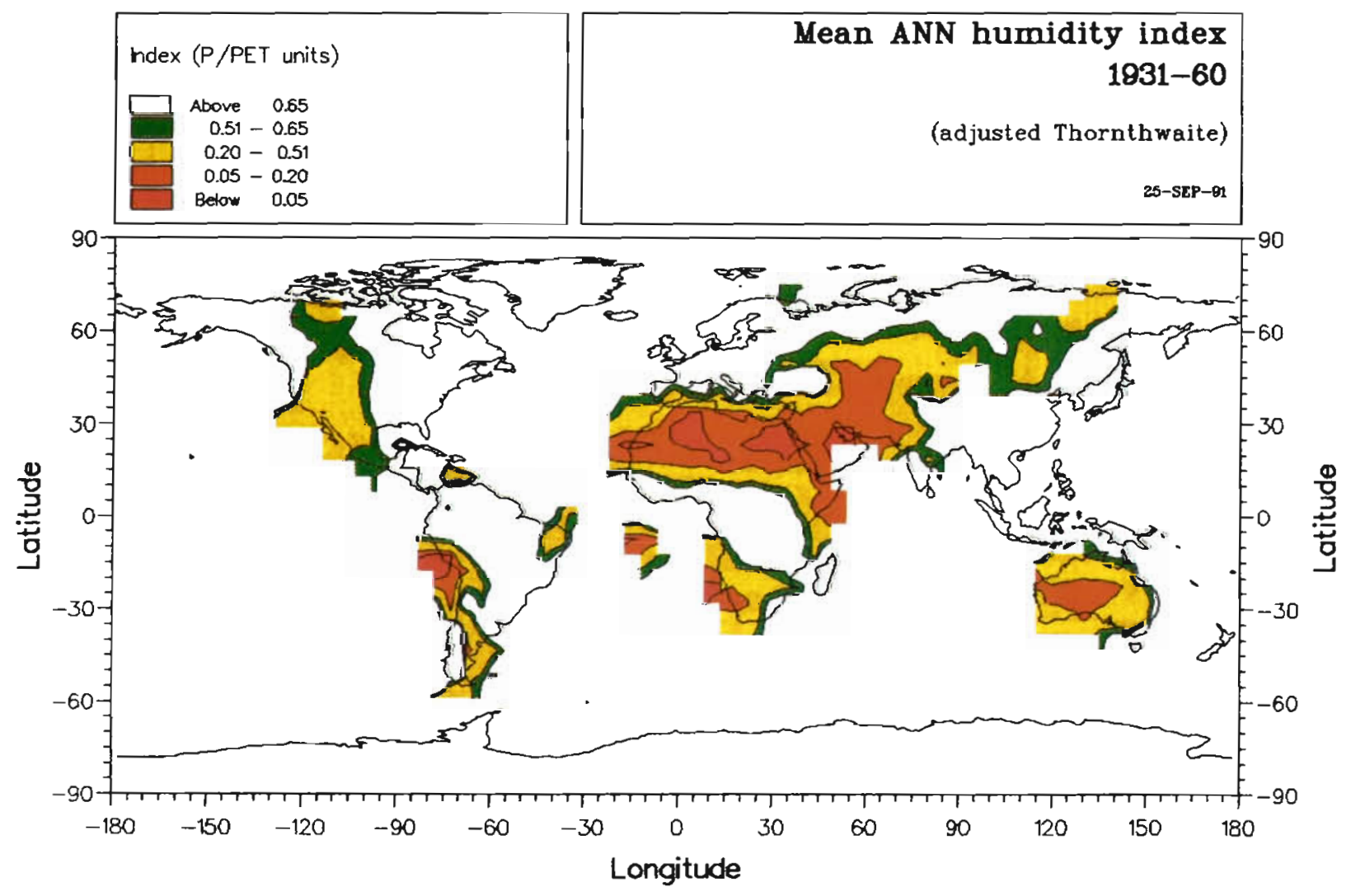

Fig. 12. Mean annual humidity index for 1931-60 using adjusted Thornthwaite PE. Contour intervals are those used by UNEP/GEMS (1992) to define dryland boundaries. Interpolation and contouring performed by UNIRAS Graphics, Version 6.0 


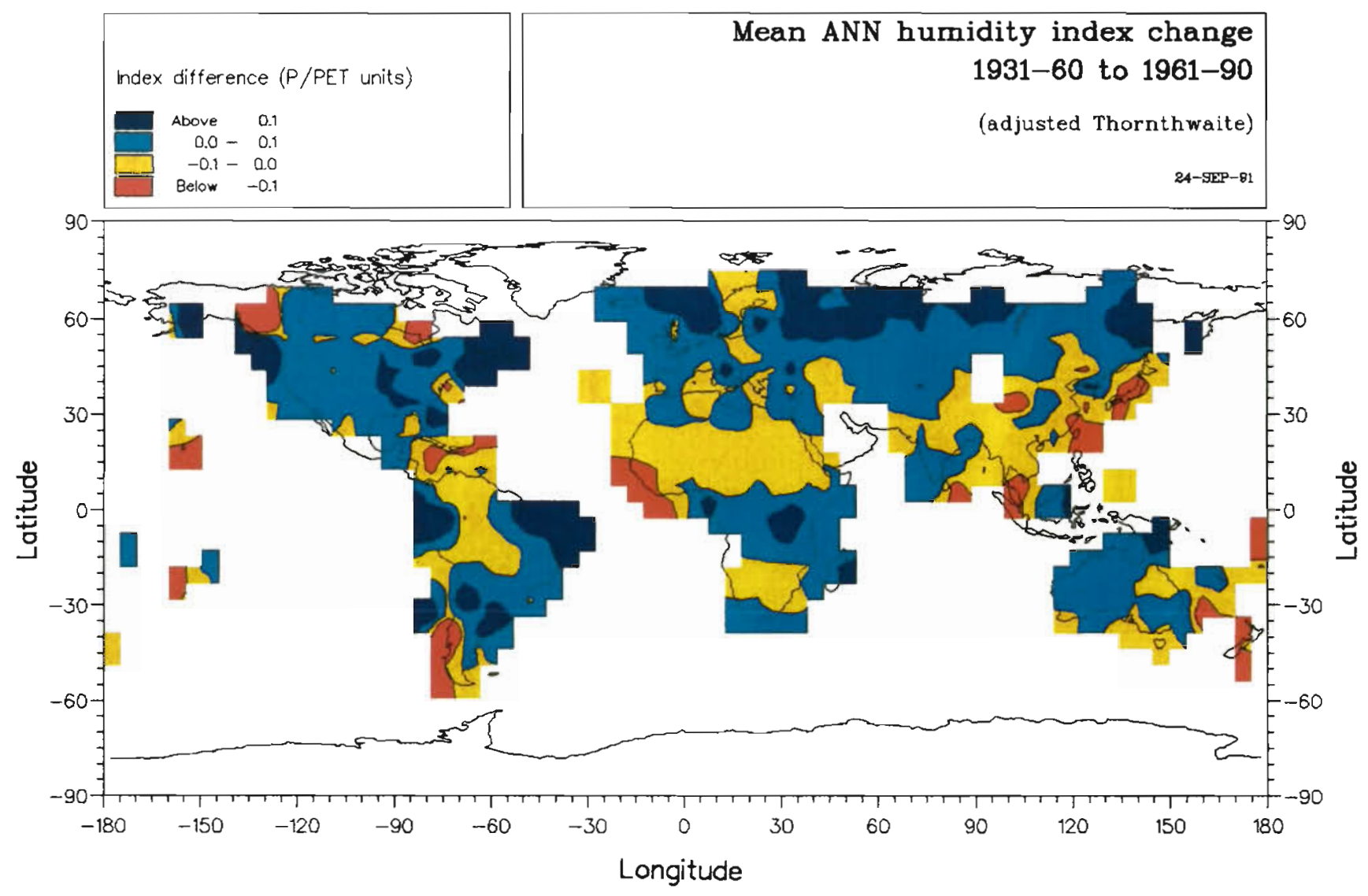

Fig. 13. Change in annual humidity index from 1931-60 to 1961-90 using adjusted Thornthwaite PE. Interpolation and contouring performed by UNIRAS Graphics, Version 6.0

tween 1931-60 and 1961-90, only $1.7 \%$ of Africa shifted into a moister zone and these movements occurred mostly south of the equator from dry sub-humid to humid.

This method provides an alternative approach to assessing desert expansion and contraction over tropical north Africa to that illustrated by Tucker et al. (1991). Using the Normalised Difference Vegetation Index (NDVI) derived from the NOAA series of satellites, they estimated the position of the $200 \mathrm{~mm}$ annual isohyet for each year from 1980 to 1990 . Using this definition of the desert boundary, they calculated that the area of the Sahara (roughly the hyper-arid and arid zones used here) varied annually during the 1980 s by up to 135 million hectares (about 16\% of the 1980 area). Since Tucker et al.'s method uses a vegetation index to determine dryland boundaries, it cannot distinguish between climatic-induced and humaninduced (such as might result from overgrazing, deforestation and changes in agricultural practises) changes to these boundaries. Although our approach (P/PE) to define dryland boundary changes would

Table 7. Change between 1931-60 and 1961-90 in area (hectares $\times 10^{6}$ ) of contiguous Africa falling within different moisture boundaries. These estimates were determined by interpolating the annual humidity index values from a $5^{\circ}$ to a $1^{\circ}$ resolution and analysing the resulting fields using the IDRISI GIS (Eastman 1990)

\begin{tabular}{|c|c|c|c|c|c|c|}
\hline \multirow{2}{*}{ Moisture zone } & \multicolumn{2}{|c|}{$1931-60$} & \multicolumn{2}{|c|}{$1961-90$} & \multicolumn{2}{|c|}{ Net change } \\
\hline & $\left(\right.$ ha $\left.\times 10^{6}\right)$ & $(\%)$ & $\left(\right.$ ha $\left.\times 10^{6}\right)$ & $(\%)$ & $\left(\right.$ ha $\left.\times 10^{6}\right)$ & $(\%)$ \\
\hline Hyper-arid & 450.8 & 15.1 & 501.5 & 16.8 & +50.7 & +1.7 \\
\hline Arid & 676.9 & 22.7 & 680.0 & 22.8 & +3.1 & +0.1 \\
\hline Semi-arid & 620.9 & 20.8 & 606.9 & 20.3 & -14.0 & -0.5 \\
\hline Dry sub-humid & 264.4 & 8.9 & 250.0 & 8.4 & -14.4 & -0.5 \\
\hline Humid & 972.4 & 32.6 & 947.0 & 31.7 & -25.4 & -0.9 \\
\hline
\end{tabular}


appear to be sensitive only to climate change, an alternative view has been suggested by Balling (1991). He argued that human-induced land cover change in dryland regions like the African Sahel has caused local increases in surface air temperature which would lead to an expansion of dryland regions according to our definition (higher temperatures, higher PE and a lower HI). If Balling is correct, a dryland expansion could occur irrespective of natural climatic change. The evidence from our analysis for this land cover-induced temperature change suggested by Balling in the African Sahel is rather poor however - annual temperatures have decreased, although summer (JJA) temperatures have increased slightly between 1931-60 and 1961-90 (see Fig. 5).

Our analysis generated maps of change in air temperature, precipitation and PE over the last 60 yr. The temperature changes have been more fully analysed elsewhere (Jones \& Briffa 1992). The implied sensitivities of terrestrial-mean precipitation and global-mean $\mathrm{PE}$ to global-mean temperature change $(\Delta \mathrm{P} / \Delta \mathrm{T}$ and $\Delta \mathrm{PE} / \Delta \mathrm{T})$ are, respectively, 17 and $7 \%$ per ${ }^{\circ} \mathrm{C}$. These sensitivities are very dependent on the global-mean warming observed between $1931-60$ and $1961-90\left(0.07^{\circ} \mathrm{C}\right)$ and should not be regarded as definitive. A decade-bydecade analysis over the period 1931-90, for example, would provide a larger sample of observed global sensitivities. The $\Delta \mathrm{P} / \Delta \mathrm{T}$ sensitivity is considerably higher than that estimated by recent GCM greenhouse experiments where the range is between 2 and $4 \%$ per ${ }^{\circ} \mathrm{C}$ (Mitchell et al. 1990). Apart from our observed sensitivity being a sample of one, the difference may be due to the incomplete sampling of the global temperature fields by the observed data analysed here, or more likely to the fact that we are considering only terrestrial precipitation and not land and ocean precipitation as in a GCM experiment. The global $\Delta \mathrm{PE} / \Delta \mathrm{T}$ sensitivity is also rather hard to interpret since the analysed fields are a combination of both ocean (evaporation will occur at the PE rate) and land areas (evaporation will be less than PE). Nevertheless, Rind et al. (1990) reported a global $\triangle P E / \Delta T$ sensitivity of $7 \%$ per ${ }^{\circ} \mathrm{C}$ for the GISS climate model experiments which is in agreement with our observed result.

We have constructed an annual humidity index, defined as $P / P E$, for 2 independent 30 yr periods representing 1931-60 and 1961-90. Values of the index have been determined for both periods on a $5^{\circ}$ resolution for about $70 \%$ of the world's land surface. The index is of necessity a crude indicator of moisture availability, but its use in defining dryland boundaries has been proven (FAO 1977) and has been used in the 1992 UNEP/GEMS global reassessment of desertification. Three main criticisms may be made of the index.

First, annual P/PE is a crude indicator of moisture availability. Seasonal or monthly values might be of greater use (these could only be determined here, however, using unadjusted Thornthwaite PE estimates) and some measure of moisture availability which incorporated vegetative moisture demand might be desirable for many applications. It nevertheless provides an easily interpreted index and is similar in conception to that used by Rind et al. (1990) in their assessment of changes in drought frequencies predicted by greenhouse climate experiments.

Second, the estimation of PE has relied upon Thornthwaite's method. This was an unavoidable necessity if $\mathrm{PE}$ estimates were to be made, from quality controlled data, for two 30 yr periods. The poor performance of Thornthwaite in dry seasons and regions was recognised and an adjustment factor derived from station data which were representative of both midand low latitudes and which covered precipitation regimes between 0 and $2000 \mathrm{~mm}$. Further testing of such an adjustment would be desirable using good quality Penman estimates of PE for cold (e.g. Canada) and very humid (e.g. Amazonia) regimes.

Third, the spatial resolution of the index is coarse. This constraint is again traced back to the rigourous data requirements of the construction method and the $60 \mathrm{yr}$ period being assessed. Undoubtedly, higher resolution humidity surfaces could be derived for specific regions with good station coverage. The adopted resolution of $5^{\circ}$ is, however, directly comparable with that used by the current generation of General Circulation Models and the data sets constructed here can be used for model validation and for constructing future scenarios of dryland boundary changes. Some of this work has already been undertaken.

Acknowledgements. The work described here was initiated by UNEP/GEMS/GRID (Nairobi) as a contribution to their 1992 global assessment of desertification. The role of Mike Norton-Griffiths in facilitating this work is acknowledged. The data sets used have been compiled with the support of research grants from the U.S. Department of Energy and the U.K. Department of Environment. Comments by one reviewer led to improvements in the clarity of the paper.

\section{LITERATURE CITED}

Awadulla, S. A. (1983). Potential evapotranspiration over the Sudan: an application of Penman's model over a dense spatial pattern. Scientific Note No. 3. Sudan Meteorological Department, Khartoum

Balling, R. C. Jr (1991). Impact of desertification on regional and global warming. Bull. Am. Meteor. Soc. 72: 232-234

Blaney, H. F., Criddle, W. O. (1950). Determining water requirements in irrigated areas from climatological and irrigation data. Soil Conservation Technical Paper No. 96 U.S.D.A., Washington, D.C.

Creutin, J. D., Obled, C. (1982). Objective analysis and mapping techniques for rainfall fields: an objective comparison. Water Resour. Res. 18: 413-431 
Delfine, P., Delhomme, J. P. (1973). Optimal interpolating by kriging. In: Davis, J. C., McCullagh, M. J. (eds.) Display and analysis of spatial data. NATO Advanced Study Institute. Wiley and Sons, London, p. 96-114

Eastman, J. R. (1990). IDRISI Version 3.2: a grid-based geographic information system. Clark University, Worcester, MA

Eischeid, J. K., Diaz, H. F., Bradley, R. S., Jones, P. D. (1991). A comprehensive precipitation data set for global land areas. Rep. No. TR051, US Dept of Energy, Washington, D.C.

FAO/UNESCO/WMO (1977). World map of desertification. FAO, Rome

Groisman, P. Ya., Koknaeva, V V., Belokrylova, T. A., Karl, T. R. (1991). Overcoming biases of precipitation measurement: a history of the USSR experience. Bull. Am. Met. Soc. 72: 1725-1733

Houghton, J. T., Jenkins, G. J., Ephraums, J. J. (eds.) (1990). Climate change: the IPCC scientific assessment. Cambridge University Press, Cambridge

Hulme, M. (1991). Analysis of worldwide precipitation records and comparison with model prediction. Final report for the UK Department of the Environment. Contract PECT/7/10/198, Climatic Research Unit, Norwich

Hulme, M. (1992). A 1951-80 global land precipitation climatology for the evaluation of general circulation models. Clim. Dyn. 7: 57-72

Hulme, M., Marsh, R. (1990). Global mean monthly humidity surfaces for 1930-59, 1960-89 and projected for 2030. Report prepared for UNEP/GEMS/GRID (Nairobi). Climatic Research Unit, Norwich

Hutchinson, M. F. (1991). The application of thin plate smoothing splines to continent-wide data assimilation. In: Jasper, J. D. (ed.) Data assimilation systems. BMRC Research Report No. 27. Bureau of Meteorology, Melbourne, p. $104-113$

Jackson, I. J. (1989). Climate, water and agriculture in the tropics, 2nd edn. Longman, Harlow

Jones, P. D. (1988). Hemisphere surface air temperature variations: recent trends and an update to 1987 . J. Climate 1 : $654-660$

Jones, P. D., Briffa, K. (1992). Global surface air temperature variations. Part I. The instrumental period. Holocene 2: $174-188$

Jones, P. D., Kelly, P. M., Goodess, C. M., Karl, T. (1989). The effect of urban warming on the Northern Hemisphere temperature average. J. Climate 2: 285-290

Jones, P. D., Raper, S. C. B., Bradley, R. S., Diaz, H. F., Kelly, P. M., Wigley, T. M. L. (1986a). Northern Hemisphere surface air temperature variations, 1851-1984. J. Clim. Appl. Meteor. 25: 161-179

Jones, P. D., Raper, S. C. B., Goodess, C. M., Cherry, B. S. G., Wigley, T. M. L. (1986b). A grid point surface air temperature data set for the Southern Hemisphere. Report No. TR027. US Department of Energy, Washington, D.C.

Jones, P. D., Raper, S. C. B., Santer, B. D., Cherry, B. S. G., Goodess, C. M., Kelly, P. M., Wigley, T. M. L., Bradley, R. S., Diaz, H. F. (1985). A grid point surface air temperature data set for the Northern Hemisphere. Report No. TR022. US Department of Energy, Washington, D.C.

Jones, P. D., Wigley, T. M. L. (1990). Global warming trends. Scient. Amer. August: 84-91

Jones, P. D., Wigley, T. M. L. (1991). The global temperature record for 1990. DOE Research Summary No. 10. Carbon Dioxide Information and Analysis Center, Oak Ridge National Laboratory
Jones, P. D., Wigley, T. M. L., Farmer, G. (1991). Marine and land temperature data sets: a comparison and look at recent trends. In: Schlesinger, M. E. (ed.) Greenhousegas-induced climatic change: a critical appraisal of simulations and observations. Elsevier, Amsterdam, p. $153-172$

Jones, P. D., Wigley, T M. L., Wright, P. D. (1986c). Global temperature variations, 1861-1984. Nature, Lond. 322: $430-434$

Karl, T R., Jones, P. D. (1989). Urban bias in area-averaged surface air temperature trends. Bull. Am. Meteor. Soc. 70 : 265-70

KNMI (Koninkijk Nederlands Meteorologish Institut) (1988). van Penman naar Makkink: een nieuwe berekeningswijze voor de klimatologische verdampingsgetallen. Technical Report No. TR-111. KNMI, de Bilt

Köppen, W. (1936). Das geographische System der Klimate. In: Köppen, W., Geiger, R. (eds.) Handbuch der Klimatologie, Vol. 3. Gebrüder Borntraeger, Berlin

Kumar, K. K., Kumar, K. R., Rakhecha, P. R. (1987). Comparison of Penman and Thornthwaite methods of estimating potential evapotranspiration for Indian conditions. Theor. Appl. Climatol. 38: 140-146

Landsberg, H. H. (1981). The urban climate. International Geophysics Series, Vol. 28. Academic Press, New York

Lebel, T., Bastin, G., Obled, C., Creutin, J. D. (1987). On the accuracy of areal rainfall estimation: a case study. Water Resour. Res. 23: 2123-2134

Legates, D. R., Willmott, C. J. (1990). Mean seasonal and spatial variability in gauge-corrected, global precipitation. Int. J. Climatol. 10: 111-128

Mather, J. R., Ambroziak, R. A. (1986). A search for understanding potential evapotranspiration. Geogr. Rev. 76 : $355-470$

Mitchell, J. F. B., Manabe, S., Meleshko, V., Tokioka, T. (1990). Equilibrium climate change and its implications for the future. In: Houghton, J. T., Jenkins, G. J., Ephraims, J. J. (eds.) Climate change: the IPCC scientific assessment. Cambridge University Press, Cambridge, p 137-164

Monteith, J. L. (1973). Principles of environmental physics. Edward Arnold, London

Müller, M. J. (1982). Selected climatic data for a global set of standard stations for vegetation science. Dr. W. Junk Publishers, The Hague

Odingo, R. S. (ed.) (1990). Desertification revisited. Proceedings of an ad hoc consultative meeting on the assessment of desertification, UNEP/DC-PAC, Nairobi, February 1990. UNEP, Nairobi

Penman, H. L. (1948). Natural evapotranspiration from open water, bare soil and grass. Proc. R. Soc. Lond. A193: 120-145

Rind, D., Goldberg, R., Hansen, J., Rosenzweig, C., Ruedy, R. (1990). Potential evapotranspiration and the likelihood of future drought. J. Geophys. Res. 95: 9983-10004

Ropelewski, C. F., Halpert, M. S. (1989). Precipitation patterns associated with the high phase of the Southern Oscillation. J. Climate 2: 268-284

Ropelewski, C. F., Jones, P. D. (1987). An extension of the Tahiti-Darwin Southern Oscillation Index. Mon. Weather Rev. 115: 2161-2165

Sevruk, B. (1982). Methods of correcting for systematic error in point precipitation measurement for operational use. Operational Hydrology Rep. No. 21, WMO No. 589 , Geneva

Thornthwaite, C. W. (1931) The climates of North America according to a new classification. Geogr. Rev. 21: 633-655 
Thornthwaite, C. W. (1948). An approach towards a rational classification of climate. Geogr. Rev, 38: 55-94

Tucker, C. J., Dregne, H. E., Newcomb, W. W. (1991). Expansion and contraction of the Sahara Desert from 1980 to 1990. Science 253: 299-301

UNEP (1984). General assessment of progress in the implementation of the Plan of Action to Combat Desertification, 1978-1984. Rep. No. UNEP/GC.12/9, Nairobi

Editor: G. Esser
UNEP (1992). World atlas of desertification. Edward Arnold, Sevenoaks

Woodruff, S. D., Slutz, R. J., Jenne, R. J., Steurer, P. M. (1987). A Comprehensive Ocean-Atmosphere Data Set. Bull. Am. Meteor. Soc. 68: 1239-1250

World Meteorological Organisation (1989). Calculation of monthly and annual 30-year standard normals. WCDPNo. 10, WMO-TD/No. 341, Geneva

Manuscript first received: December 4, 1991 Revised version accepted: April 30, 1992 